\title{
Lysosomal Biology and Function: Modern View of Cellular Debris Bin
}

\author{
Purvi C. Trivedi ${ }^{1,2}$, Jordan J. Bartlett ${ }^{1,2}$ and Thomas Pulinilkunnil ${ }^{1,2, *(\mathbb{B})}$ \\ 1 Department of Biochemistry and Molecular Biology, Dalhousie University, Halifax, NS B3H 4H7, Canada; \\ purvi.trivedi@dal.ca (P.C.T.); jjeffreyb@mun.ca (J.J.B.) \\ 2 Dalhousie Medicine New Brunswick, Saint John, NB E2L 4L5, Canada \\ * Correspondence: tpulinil@dal.ca; Tel.: +1-(506)-636-6973
}

Received: 21 January 2020; Accepted: 29 April 2020; Published: 4 May 2020

\begin{abstract}
Lysosomes are the main proteolytic compartments of mammalian cells comprising of a battery of hydrolases. Lysosomes dispose and recycle extracellular or intracellular macromolecules by fusing with endosomes or autophagosomes through specific waste clearance processes such as chaperone-mediated autophagy or microautophagy. The proteolytic end product is transported out of lysosomes via transporters or vesicular membrane trafficking. Recent studies have demonstrated lysosomes as a signaling node which sense, adapt and respond to changes in substrate metabolism to maintain cellular function. Lysosomal dysfunction not only influence pathways mediating membrane trafficking that culminate in the lysosome but also govern metabolic and signaling processes regulating protein sorting and targeting. In this review, we describe the current knowledge of lysosome in influencing sorting and nutrient signaling. We further present a mechanistic overview of intra-lysosomal processes, along with extra-lysosomal processes, governing lysosomal fusion and fission, exocytosis, positioning and membrane contact site formation. This review compiles existing knowledge in the field of lysosomal biology by describing various lysosomal events necessary to maintain cellular homeostasis facilitating development of therapies maintaining lysosomal function.
\end{abstract}

Keywords: lysosome; metabolism; autophagy; endocytosis; mannose-6-phosphate; cathepsin; calcium; proton

\section{Introduction}

Seminal studies by Duve Laboratory uncovered lysosome as the cellular compartment for the degradation of biological macromolecules [1,2]. Endocytic [3,4], autophagic $[5,6]$ and phagocytic $[7,8]$ pathways facilitate macromolecule degradation within the lysosome. Acid hydrolases and lysosomal membrane proteins (LMPs) dictate lysosomal function $[9,10]$. The acidity of the lysosome stabilizes and mediates the activity of $\sim 60$ luminal hydrolytic enzymes. The lysosomal limiting membrane harbors 25 LMPs, which include transporters, trafficking/fusion machinery, ion channels and structural proteins [10]. LMPs are pivotal in maintaining lysosomal membrane integrity, luminal acidification, an ionic gradient and homeostasis, protein translocation and membrane trafficking [9,10]. In addition, lysosomes contain ions and harbor ion channels, which exert an indispensable role in regulating lysosomal $\mathrm{pH}$ and function [11].

Beyond the lysosome's canonical role in cellular waste disposal, it is also implicated in nutrient sensing, immune cell signaling, metabolism, and membrane repair [12]. Emerging studies show that intra-lysosomal and extra-lysosomal processes govern lysosomal fusion and fission [13], exocytosis [14], positioning [15] and formation of a membrane contact site [16]. Lysosome fusion and fission influence lysosome number, size and exocytosis [13-15]. Furthermore, depending on cellular metabolic requirements, or activation by distinct stimuli, lysosomes mobilize to either the cell periphery or to 
the perinuclear region [15]. Lysosomes also form a membrane contact site with other organelles to exchange signaling information, shuttle metabolites and render ionic homeostasis $[16,17]$. Perturbation in lysosomal function is observed in lysosomal storage disorders, neurodegenerative conditions, cancer, and cardiovascular and metabolic diseases. This review compiles existing knowledge in the field of lysosomal physiology and function by describing lysosomal events necessary in maintaining lysosome function and cellular homeostasis.

\section{Lysosome Biogenesis}

Lysosomes are $0.2-0.3 \mu \mathrm{m}$ in diameter. Primary lysosomes originate from the Golgi apparatus. Current literature describes multiple models of lysosomal biogenesis. The first model of lysosome biogenesis describes the formation of early endosomes (EEs) from the plasma membrane, and their progressive maturation to late endosomes (LEs) and lysosomes [18,19]. The second model involves vesicular transport, where endosomal carrier vesicle/multivesicular bodies (ECV/MVBs) transfer cargo from early to late endosomes to lysosomes or directly from the matured LEs to lysosomes $[18,19]$. The third model denotes the "kiss and run" event wherein, LEs ("kiss") form a contact site with lysosomes transferring cargo with ensuing dissociation ("run") of lysosomes and LEs $[18,19]$. The fourth model of lysosome biogenesis is purported to be a fusion-fission event involving a heterotypic fusion of LEs-lysosomes to form hybrid organelles, followed by lysosome re-formation (Figure 1).

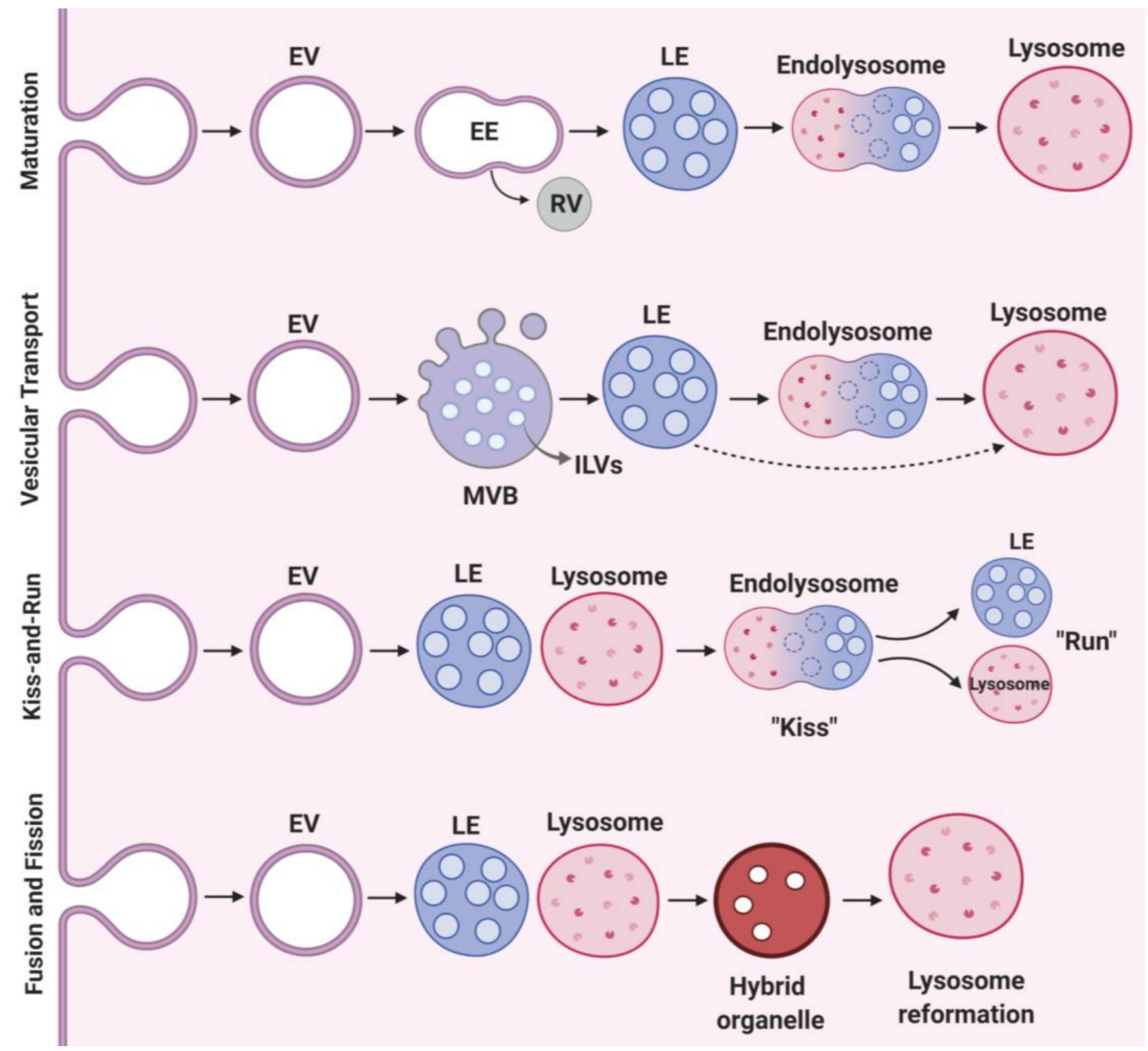

Figure 1. Molecular events in lysosome biogenesis. Maturation; this model of lysosome biogenesis describes the formation of EVs (endocytic vesicles) from the plasma membrane and their progressive maturation to late endosomes and subsequently to lysosomes. The cargo targeted for recycling is carried by the TGN derived RVs (recycling vesicles), whereas cargo required for lysosomal degradation 
is transported by the cargo vesicle through late endosomes. Vesicular transport; requires ECV/MVBs (endosomal carrier vesicle/multi-vesicular bodies) carrying ILVs (intraluminal vesicles), which mobilize cargo from early-to-late endosomes and then to lysosomes or mobilize cargo directly from the matured late endosomes to lysosomes. Kiss-and-Run; describes contact site formation between lysosomes and late endosomes ("kiss") followed the by cargo transfer and ensuing dissociation ("run") of late endosomes from lysosomes. Fusion and fission; events involve heterotypic fusion of late endosome-lysosome to form a hybrid organelle and subsequently lysosome reformation.

\subsection{Sorting}

Lysosomal enzyme precursors are biosynthesized in the rough endoplasmic reticulum and modified in the Golgi apparatus [20]. Newly synthesized enzymes are initially tagged with mannose-6-phosphate residues, targeting them for specific binding to the mannose-6-phosphate receptors (M6PRs) in the trans-Golgi network (TGN). Subsequently, enzymes tagged with M6PRs are packed into plasma membrane localized clathrin-coated vesicles (CCVs) for biosynthetic transport to LEs either directly or indirectly via EEs [21,22]. Sorting begins by budding and fusion of CCVs with each other or with pre-existing EEs to deliver and sort endocytic cargo [10,23].

EEs have acidic intraluminal $\mathrm{pH}$, facilitating uncoupling of ligands from M6PRs and allowing migration towards LEs and lysosomes [4]. Unbound M6PRs are either transported back from endosomes-to-TGN via endosomal vacuoles or are recycled via tubular-sorting endosomes (TSEs) [21,22]. This retrograde recovery of M6PRs from endosome-to-TGN occurs via a "retromere", which is a penta-unit structure that encodes vacuolar protein sorting (VPS) genes [21]. Structurally, a retromere is comprised of a dimer of sorting nexin proteins, which include SNX1/2 (Vps5-Vps17 in yeast) and a trimeric core of Vps35-Vps29-Vps26 referred to as a cargo-selective complex (CSC) [24]. Monomeric G proteins like RAB GTPases, such as Rab5 and Rab7, regulate the association of retromeres with EEs [25]. Loss of Rab7 function destabilizes the trimeric structure of the retromere, disrupting M6PR recycling and acid hydrolase sorting, impairing EE-to-LE maturation and disrupting cargo degradation [26]. Unlike lysosomal hydrolases that bind with M6PRs, LMPs are delivered either directly to endosomes and lysosomes (direct pathway) or indirectly to the plasma membrane and then to endosomes and lysosomes (indirect or salvage pathway) [27].

The sorting of acid hydrolases and LMPs requires the heterotetrameric adaptor protein complex AP1, AP2, AP3 and AP4, each composed of four adaptin subunits. Specific localization of AP governs sorting of M6PRs and LMPs and thereby lysosome biogenesis. AP1 is localized to the TGN and endosomes and assists in the recycling of M6PRs within the TGN. AP2 and AP3 are located on the plasma membrane and endosomes respectively, aiding the transportation of LMPs to lysosomes. Loss of AP3 function in Hermansky-Pudlak syndrome 2, causes redistribution of LMPs to the plasma membrane and impairs lysosome biogenesis in melanosomes and platelet dense granules [28,29].

\subsection{Vesicular Transport and Maturation}

Transport from early to late endosomes involves selective sorting events to facilitate cargo movement into the lysosome. Multivesicular endosomes/bodies (MVBs) are endosomes that contain intraluminal vesicles (ILVs) (Figure 1). Progressive accumulation of ILVs and sorting of lysosome-directed proteins onto ILVs characterizes typical MVBs maturation. The cargo proteins destined for degradation are ubiquitinated and recognized by the ESCRT complex (endosomal sorting complexes required for transport), driving the ILV biogenesis necessary for sorting cargo proteins. When multiple rounds of membrane fusion and fission occur, EEs enriched in ILVs are structurally remodeled to form globular LEs and subsequently lysosomes for degradation. Vesicular transport and maturation of EEs to LEs depend on the conversion of Rab5 to Rab7. As EEs progressively mature and acidify into LEs, they move from cell periphery to cell center. During maturation, EEs lose Rab5 on their membrane and gain Rab7, underscoring the importance of Rab proteins in the EE-to-LE maturation process [26]. 
Additionally, maturation of EEs to LEs/lysosomes requires v-ATPase, a proton pump that acidifies $\mathrm{LEs} / \mathrm{lysosomes}$ to a $\mathrm{pH}$ of $\approx 5.5 / 5.0$. In addition to proton homeostasis, ionic $\mathrm{Ca}^{2+}$ balance within LEs and lysosomes is indispensable for endo-lysosomal functions including receptor-ligand uncoupling and lysosomal enzyme transport and activity. Indeed, homotypic (fusion of early and late endosomes) and heterotypic (fusion of LEs and lysosomes) fusion are dependent on the $\mathrm{Ca}^{2+}$-calmodulin complex. This was shown via cell-free experiments, where endosome-lysosome fusion was suppressed by treating cells with either BAPTA (1,2-bis(o-aminophenoxy)ethane- $\mathrm{N}, \mathrm{N}, \mathrm{N}^{\prime}, \mathrm{N}^{\prime}$-tetraacetic acid; binds to $\mathrm{Ca}^{2+} 100$ times faster) or an ester form of EGTA-AM (ethylene glycol-bis( $\beta$-aminoethyl ether)- $\mathrm{N}, \mathrm{N}, \mathrm{N}^{\prime}, \mathrm{N}^{\prime}$-tetraacetic acid-Acetoxymethyl ester; $\mathrm{AM}$ dissociates within the lumen leading to luminal $\mathrm{Ca}^{2+}$ chelation) but not with EGTA (exchanges $\mathrm{Ca}^{2+} \sim 100$ times slower than BAPTA).

\section{Lysosomal Enzymes}

Lysosomes are abundant in hydrolytic enzymes such as proteases, sulfatases, nucleases, lipases, phosphatases, glycosidases and nucleases, all of which degrade complex macromolecules. Lysosomal enzymes have optimal activity at $\mathrm{pH} 5$.

\subsection{Cathepsin Proteases}

Discovered in the gastric fluid in 1929, cathepsin literally means to digest or boil down. According to their structure and catalytic activity, cathepsins are classified into serine cathepsins (A and G), aspartic cathepsins (D and E) and cysteine cathepsins. Among the cathepsins, the most highly characterized proteases are cysteine proteases, which consist of 11 cathepsins (B, C/DPP1, F, H, L, K, O, S, V, W and X) (Figure 2) [30,31]. Cathepsin activity is regulated by transmembrane protein presenilin 1 (PS1) that targets the V0a1 subunit of v-ATPase to maintain an intraluminal acidic environment, which is vital for the stability of lysosomal proteases. Similarly, the abelson (Abl) family of cytoplasmic non-receptor tyrosine kinases, including Abl1 and 2, also govern autophagy and lysosome proteolytic activity [32]. Indeed, loss of function of Abl1 in A549 alveolar carcinoma cells leads to suppression of lysosomal enzymatic activity and impairs lysosome localization and motility, leading to the accumulation of autophagosomes [32].

Proteases play an integral role in proteolytic processing, protein modification and degradation of low-density lipoproteins (LDL) [33-35]. Human macrophages and smooth muscle cells incubated with lysosomal protease stimulator, zymosan, experience accelerated LDL hydrolysis to apolipoprotein B-100 and triglycerides (TAGs), triggering the formation of foam cells, an effect sensitive to protease inhibitor pepstatin A [36]. Mice deficient in cathepsin B or cathepsin $L$ are resistant to inflammation and atherosclerosis upon cholesterol crystal injection [37,38]. Comparatively, cathepsin $G$, an angiotensin II-forming serine protease, displays elastolytic activity in mast cells, causing adverse remodeling and progression to aortic stenosis $[39,40]$. These findings highlight the role of cathepsin proteases in the pathogenesis of atherosclerosis-based valvular diseases (Figure 2). Furthermore, mice with combined deficiency of cathepsin B and L display an accumulation of endo-lysosomes in the brain, leading to brain atrophy and death in the second and fourth week of life [41]. This study highlights the role of lysosomal proteases in central nervous system maturation during the postnatal period. Cathepsins B and D also facilitate receptor-mediated endocytosis of insulin in rat liver [42], whereas cathepsins B and D degrade insulin-like growth factor (IGF) in MG-83 [43] and HepG2 [44] cells. Notably, cathepsin $\mathrm{L}$ is involved in the proteolysis of IGF binding proteins (IGFBPs) in mouse dermal fibroblast [45], suggesting that lysosomal cysteine proteases are critical for growth factor signaling by influencing receptor-mediated growth factor degradation.

Lysosomal proteases also play a significant role in regulating macroautophagy. The ubiquitin-like conjugation system aids in the processing of Atg8, a step crucial for autophagosome formation. In yeast, autophagosomal formation is aided by cysteine protease Atg4, which cleaves the C-terminus of Atg8 (GABARAP, LC3 and GATE-16, mammalian Atg8 homologs). Subsequently, Atg8 conjugates with PE (phosphatidylethanolamine) to form Atg8-PE complex, a process catalyzed by Atg7 and Atg3 [46-48]. 
Aspartic protease cathepsin E assists in lysosomal autophagy by regulating lysosomal luminal $\mathrm{pH}$, independent of its action on v-ATPase activity [49]. Indeed, mouse macrophages deficient in Cathepsin E accumulate lysosomal membrane proteins with increased lysosomal $\mathrm{pH}$ [49], phenocopying lysosomal storage disorders. Together, these studies signify that cathepsin proteases are essential for lysosomal autophagy function and help in maintaining lysosomal structural integrity.
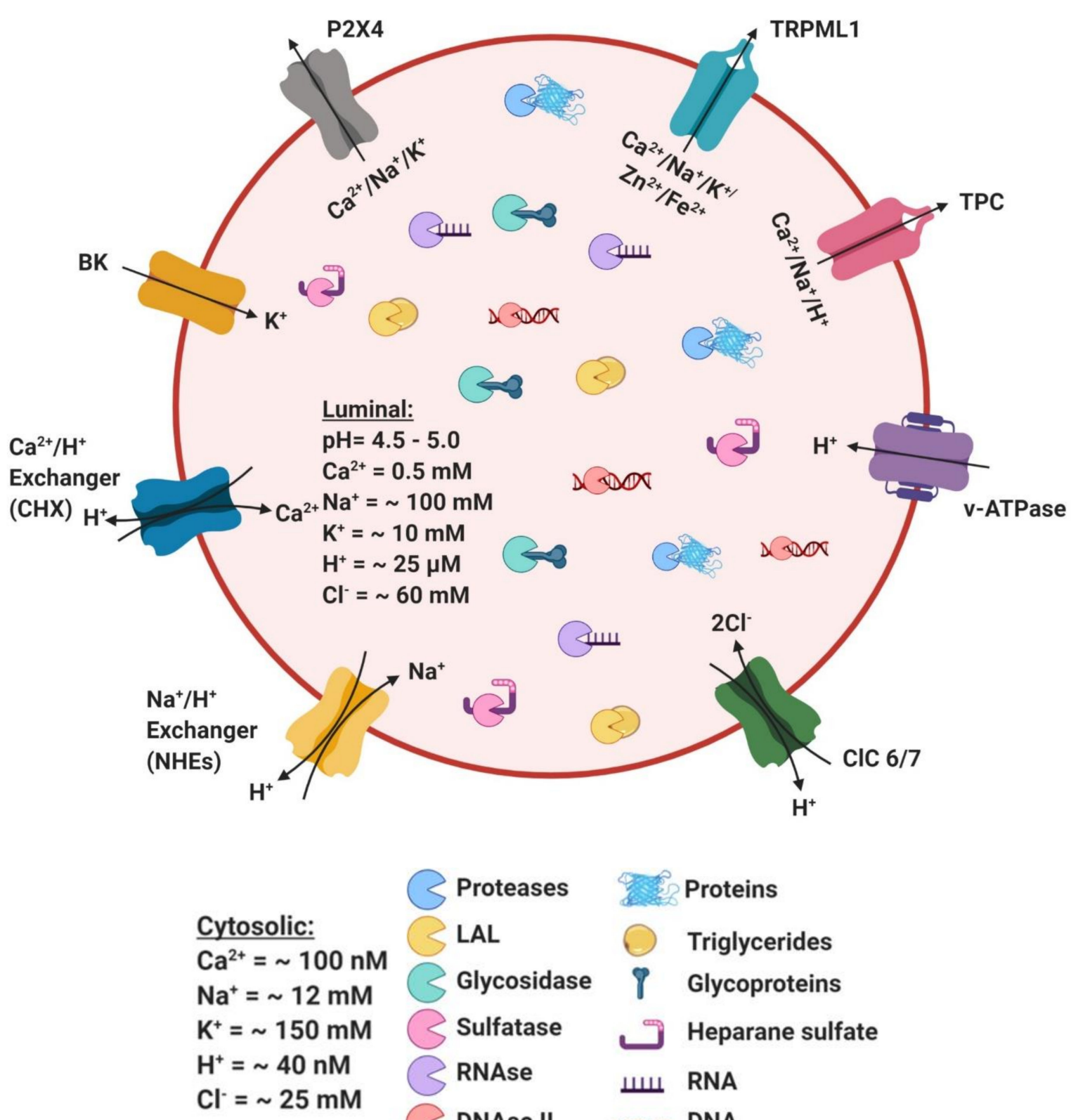

Proteases

LAL

Glycosidase 9 Glycoproteins

Sulfatase

RNAse

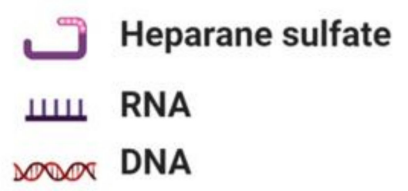

Figure 2. Lysosome ion channels and transporters. The lysosomal lumen contains a battery of soluble hydrolytic enzymes that degrade proteins (proteases), triglycerides (lysosomal acid lipase; LAL), glycoproteins (glycosidases), heparan sulphate (sulfatases), and nucleic acids (nucleases, RNAase and DNAse). Lysosomal ion channels and transporters include vATPase; vacuolar $\mathrm{H}^{+}$-ATPase (proton pump), chloride channel (ClC); $\mathrm{ClC}$ family that exchanges cytosolic $\mathrm{Cl}^{-}$for lysosomal $\mathrm{H}^{+}(\mathrm{ClC}-6$ and ClC-7), $\mathrm{K}^{+}$channels (BK). Non-selective cation channels include Transient Receptor Potential Cation Channel (TRPML); permeable to $\mathrm{Ca}^{2+}, \mathrm{Na}^{+}, \mathrm{K}^{+}, \mathrm{Zn}^{2+}$ and $\mathrm{Fe}^{2+}, \mathrm{P} 2 \mathrm{X} 4$ channel; permeable to $\mathrm{Ca}^{2+}$, $\mathrm{Na}^{+}$and $\mathrm{K}^{+}$and two-pore channels (TPC); permeable to $\mathrm{H}^{+}, \mathrm{Ca}^{2+}$ and $\mathrm{Na}^{+}$. Ion transporters include $\mathrm{Na}^{+} / \mathrm{H}^{+}$exchangers (NHEs) and $\mathrm{Ca}^{2+} / \mathrm{H}^{+}$exchangers (CHX). 


\subsection{Lysosomal Acid Lipases (LAL)}

Encoded by lipase A (LIPA), LAL plays a critical role in energy metabolism, signaling and structural integrity of cell membranes [50]. LAL is primarily responsible for hydrolyzing lipoprotein cholesteryl esters (CEs) and triglycerides (TAGs) to free cholesterol (FC) and fatty acids (FAs), respectively (Figure 2). LAL hydrolyzes exogenous and endogenous neutral lipids, which are primarily delivered to the lysosome either through endocytosis of lipoproteins or through autophagy (also known as lipophagy) [51,52].

Under physiological conditions, LAL hydrolyzes acetylated-LDL containing CEs into FC, which can be primarily stored as a lipid droplet or used for membrane assembly. On the other hand, oxidized-LDL is a poor substrate for LAL, causing retention of both CEs and FC within the lysosome of foam cells promoting atherogenesis. Lysosomal cholesterol accumulation is associated with the pathogenesis of atherosclerosis $[53,54]$. Electron microscopy within an atherosclerotic lesion reveals lipid-laden lysosomes both in human lesions [55,56] and in animal models of atherosclerosis [57-59]. Importantly, overload of CEs and FC increases lysosomal luminal $\mathrm{pH}$ by inhibiting vATPase, resulting in loss of LAL hydrolytic activity [50]. LAL deficiency or inactivity causes Wolman disease (WD), which has infant-onset and is fatal, whereas CE storage disease (CESD) has a later-onset due to residual (5-10\%) LAL activity manifested in patients with hyperlipidemia, hepatosplenomegaly and premature atherosclerosis $[60,61]$. Notably, recent genome-wide association studies have identified coding LIPA variant with altered processing of LAL signal peptide associated with coronary artery disease. Furthermore, macrophages from individuals with the risk-LIPA coding allele exhibit increased degradation of LAL, resulting in reduced LAL expression and LAL activity compared to the non-risk allele [57]. LAL-deficient mice injected with human recombinant LAL (rhLAL) shows reversal of pathogenic lipid accumulation during atherosclerosis [62]. Sebelipase alfa, an rhLAL, is currently FDA approved for the treatment of Wolman disease and CESD [63,64]. However, it is still not clear whether rhLAL therapy is suitable to treat patients with atherosclerosis unrelated to LAL deficiency. T cell proliferation and maturation in the thymus is abolished by inhibition of CEs and TAG metabolism in LAL-deficient mice, triggering organ inflammation and damage [65]. LAL-deficient mice also exhibit substantial accumulation of CEs and TAGs in the liver [66], adrenal glands, and small intestine with progressive loss of both white and brown adipose tissue [67]. Additionally, TAG hydrolysis liberates free FAs, which are essential for M2 macrophage activation and resistance to infection. Conversely, inhibition of LAL-dependent lipolysis suppresses immunity against pathogens [52]. Together, these findings suggest that LAL and its lipid mediators are essential for immune cell maturation and function by playing a key role in cellular differentiation and metabolism.

\subsection{Sulfatases}

Sulfatases are an evolutionarily-conserved enzyme family classified into non-lysosomal and lysosomal sulfatases based on their subcellular localization and $\mathrm{pH}$ preference $[68,69]$. Sulfatases catalyze the hydrolysis of glycosaminoglycans, including heparin, heparan sulphate, dermatan and keratan sulphate, sulfolipids (cerebroside-3-sulphate) and sulphated hormones (dehydroepiandrosterone-3-sulphate) (Figure 2), which play a critical role in cellular degradation, signaling and hormone function $[68,69]$. Sulfatase activation require $C_{\text {alpha }}$-formylglycine (FGly) in their catalytic site, and mutations at this site lead to multiple sulfatase deficiencies characterized by severe metabolic and developmental abnormalities $[68,70]$. While transporting to the final endo-lysosomal compartment, sulfatases become heavily glycosylated in the ER and Golgi, and processed via the secretory pathway [68].

\subsection{Nucleases}

Nucleases degrade RNA and DNA delivered to the lysosome via a process known as RNautophagy/DNautophagy (RDA) (Figure 2) [71]. Notably, lysosomal membrane protein LAMP2C 
facilitates the translocation of nucleic acids to the lysosome [72,73]. LAMP2 knockout mice exhibit impairment in RDA activity, whereas LAMP2C-overexpressed lysosomes display higher RDA activity [72,73]. Furthermore, LAMP2C directly binds to RNA and DNA before translocation to the lysosomal lumen [72,73], where they are degraded via lysosomal nucleases, RNase T2 and DNase II, respectively $[74,75]$. RNase T2 is a ribonuclease enzyme that cleaves single-stranded RNA into mono- or oligo-nucleotides, whereas the human homolog RNASET2 cleaves poly-A and poly-U oligonucleotides [74,76]. Hey4 cells (ovarian tumor cell line) transfected with RNASET2 demonstrate that RNASET2 is produced as a full-length nuclease in the secretory granules localized at the lysosome and exhibit optimal catalytic activity in acidic $\mathrm{pH}[74,76]$. Likewise, DNase II is an endonuclease enzyme localized in the acidic lumen of the lysosome and is responsible for cleaving double-stranded DNA [75].

\section{Ionic Balance in Lysosome Function}

Lysosomal ionic gradient is indispensable for intraluminal acidification, acid hydrolase stability and macromolecule degradation. Lysosomal ions are involved in lysosome biogenesis, motility, membrane contact site formation, and lysosome homeostasis. The lysosomal lumen is comprised of various ions including $\mathrm{Ca}^{2+}, \mathrm{Na}^{+}, \mathrm{K}^{+}, \mathrm{Zn}^{2+}, \mathrm{H}^{+}$and $\mathrm{Fe}^{2+}$ (Figure 2).

\section{1. $\mathrm{Ca}^{2+}$}

The lysosomal luminal concentration of $\mathrm{Ca}^{2+}$ is $\sim 0.5 \mathrm{mM}$, which is 5000 -fold higher than the cytosolic $\mathrm{Ca}^{2+}$ store. The endosomal and lysosomal $\mathrm{Ca}^{2+}$ flux is $\mathrm{pH}$ dependent and is essential for signal transduction, organelle homeostasis and acidification [77-79]. $\mathrm{Ca}^{2+} / \mathrm{H}^{+}$exchangers $(\mathrm{CHX})$ purportedly maintain the lysosomal $\mathrm{Ca}^{2+}$ gradient, wherein $\mathrm{Ca}^{2+}$ is transported into the lysosomal lumen in exchange for the removal of a proton [80]. $\mathrm{Ca}^{2+}$ is required for endosome-lysosome fusion, an effect sensitive to $\mathrm{Ca}^{2+}$ chelators, such as BAPTA and EGTA-AM [81]. Fused organelles (LEs-lysosomes) treated with EGTA-AM or bafilomycin A1, exhibit reduced lysosome re-formation, suggesting that both luminal lysosomal $\mathrm{Ca}^{2+}$ and acidic $\mathrm{pH}$ are indispensable for lysosome maturation [82]. Lysosomal $\mathrm{Ca}^{2+}$ also regulates lysosomal mobilization, exocytosis, membrane/vesicle trafficking and membrane contact site formation [79].

\section{2. $\mathrm{H}^{+}$}

Lysosome function is dependent on luminal acidification, since acidic $\mathrm{pH}$ renders lysosomal hydrolases stable and active, facilitating macromolecule degradation and vesicular trafficking $[18,83]$. Vacuolar $\mathrm{H}^{+}$-ATPase, a proton pump localized on the lysosomal limiting membrane, enables $\mathrm{H}^{+}$flux into the lysosomal lumen to maintain a pH of $\sim 4.6$ [84]. The luminal concentration of $\mathrm{H}^{+}$to achieve this $\mathrm{pH}$ is $25 \mu \mathrm{M}$ (Figure 2), and roughly 500 times higher than cytosolic $\mathrm{H}^{+}$levels, which is necessary for lysosomal trafficking and content condensation during membrane fission [84]. Importantly, lysosomal luminal $\mathrm{H}^{+}$content, luminal $\mathrm{pH}$ and activity of the vATPase proton pump are determined by the location of lysosomes and nutrient status of the cell [85]. Studies in Hela cells suggest that peripheral lysosomes are more alkaline than juxtanuclear lysosomes [85].

\section{3. $\mathrm{Na}^{+} / \mathrm{K}^{+}$}

Prior studies suggested that when compared to, $\mathrm{Na}^{+}$content is lower in the lysosomal lumen compared to $\mathrm{K}^{+}$ionic content [86]; however, using ultracentrifugation and mass spectroscopy, it was later deduced that luminal $\mathrm{Na}^{+}$concentration is actually higher than $\mathrm{K}^{+}$[87]. The luminal $\mathrm{Na}^{+}$concentration ranges from 20 to $140 \mathrm{mM}$, whereas $\mathrm{K}^{+}$concentration ranges from 2 to $50 \mathrm{mM}$ (Figure 2), making $\mathrm{Na}^{+}$ the most abundant cation within the lysosome [87]. Lysosomal uptake of $\mathrm{Na}^{+}$in exchange for a proton occurs via $\mathrm{Na}^{+} / \mathrm{H}^{+}$exchangers (NHEs) such as NHE3, NHE5 and NHE6 [84,88]. The major function of the $\mathrm{Na}^{+}$cation is to maintain the lysosomal membrane potential $\Delta \psi=\psi_{\text {cytosol }}-\psi_{\text {lysosome, }}$ determined 
by the ionic gradient between the lysosomal lumen and cytosol, as well as ionic permeabilities across the lysosomal membrane [11]. Increased $\mathrm{Na}^{+}$and $\mathrm{K}^{+}$flux within the lysosome hyperpolarizes the lysosomal membrane, perturbing lysosomal luminal $\mathrm{H}^{+}$gradient and acidification [11].

\section{4. $\mathrm{Cl}^{-}$}

The lysosomal luminal $\mathrm{Cl}^{-}$concentration is estimated to be $\sim 60-80 \mathrm{mM}$ (Figure 2), the most abundant anion within the lysosome [89]. Among the $\mathrm{Cl}^{-}$transporters, $\mathrm{ClC}-7$ is the primary transporter localized on the lysosome and is ubiquitously expressed, whereas $\mathrm{ClC}-6$ is a second major lysosomal $\mathrm{Cl}^{-}$transporter that is expressed in the central and peripheral nervous system [89,90]. Silencing ClC-7 in Hela cells suppresses $\mathrm{Cl}^{-} / \mathrm{H}^{+}$antiporter activity and impairs lysosomal luminal acidification suggesting that $\mathrm{ClC}-7$ is important for lysosome function [84,90]. However, loss of $\mathrm{ClC}-7$ in neurons has been implicated in the pathogenesis of lysosomal storage diseases and in neurodegeneration independent of its effect on lysosomal $\mathrm{pH}[86,91]$. These studies indicate that $\mathrm{ClC}-7$-mediated effect on lysosomal luminal $\mathrm{pH}$ is likely cell-specific.

\section{5. $\mathrm{Fe}^{2+}$ and $\mathrm{Zn}^{2+}$}

$\mathrm{Fe}^{3+}, \mathrm{Fe}^{2+}, \mathrm{Zn}^{2+}$ and $\mathrm{Cu}^{2+}$ are in micromolar concentrations within the lysosomal lumen (Figure 2). Metal ions can be released from the lysosome via proteolysis or via endocytosis or autophagocytosis of metal-bound proteins [92]. $\mathrm{Fe}^{2+}$ ion-dependent increases in ROS level aids in the survival of lysosome-resident pathogens; therefore, the levels of $\mathrm{Fe}^{2+}$ ions are under tight regulation through its binding to ferritin. [93]. Lysosome-autophagy is important in regulating intracellular levels of $\mathrm{Fe}^{2+}$. By the process of ferritinophagy, nuclear receptor coactivator 4 (NCOA4) recognizes and delivers ferritin bound $\mathrm{Fe}^{2+}$ to the lysosome [94-97]. Within the lysosome, ferritin is degraded and $\mathrm{Fe}^{2+}$ is released into the cytosol through the TRPML1 channel in both mammals and flies [96,98]. Similarly, intracellular $\mathrm{Zn}^{2+}$ levels are also regulated by $\mathrm{Zn}^{2+}$ transporters $\mathrm{ZnT} 2$ and $\mathrm{ZnT} 4$, which deliver $\mathrm{Zn}^{2+}$ to the lysosome $[99,100]$. Subsequently, $\mathrm{Zn}^{2+}$ is retrogradely transported into the cytosol through TRPML1 channel [101]. Furthermore, loss of function of TRPML1 leads to lysosomal $\mathrm{Zn}^{2+}$ deposition, triggering growth defects, impairing immune responses and causing neurogenerative diseases [101]. Therefore, lysosome activity-dependent regulation of cell proliferation requires iron homeostasis [94].

\section{Role of Ion Channels in Lysosomal Function}

Ionic movement is maintained by channels and transporters located on the lysosomal membrane, which is pertinent to ensure proper ionic homeostasis within the lysosomal lumen. There are three lysosomal $\mathrm{Ca}^{2+}$ channels in mammals: TRPML1-3, TPC1-2 and P2X4 which play a key role in regulating lysosomal activity and function (Figure 2).

\subsection{Transient Receptor Potential Cation Channel, Mucolipin Subfamily (TRPML)}

Mammalian mucolipin family belonging to the large superfamily of transient receptor potential (TRP) consists of three non-selective cation channels, TRMPL1, TRPML2 and TRPML3. TRPML1 is exclusively localized to lysosomes and is ubiquitous, TRPML2 is localized on endosomes, and TRPML3 is found on both lysosomes and endosomes [102,103]. Structurally, TRPML channels consist of four subunits, which include cytosolic $\mathrm{N}$ - and C-termini with six-transmembrane domains. TRPML channels are permeable to $\mathrm{Ca}^{2+}, \mathrm{Na}^{+}, \mathrm{K}^{+}, \mathrm{Fe}^{2+}$ and $\mathrm{Zn}^{2+}$ (Figure 2) [11]. Upon activation, TRPML channel releases $\mathrm{Ca}^{2+}$ from the endo-lysosomal lumen to regulate various physiological processes such as endo-lysosomal membrane formation, phagocytosis, lysosome biogenesis, autophagy and exocytosis. Lysosomal $\mathrm{Ca}^{2+}$ efflux via mucolipin-1 (MCOLN1) activates calcineurin, leading to phosphatase-dependent increases in nuclear translocation of transcription factor EB (TFEB), that subsequently upregulates lysosome biogenesis and autophagy [104]. Additionally, increases in reactive oxygen species (ROS) can activate TRPML1 channels to facilitate lysosomal $\mathrm{Ca}^{2+}$ release and promote 
nuclear translocation of TFEB, which scavenge ROS via lysosomal autophagy [105]. TRPML channels have also been implicated in regulating lysosomal exocytosis, as described later in this review.

Mucolipidosis type IV (MLIV) is a genetic lysosomal storage disorder (LSD) in children resulting in neurodegeneration and muscular dystrophy due to a loss of function mutation in TRPML1. Similarly, MLIV deficiency in Drosophila inhibits autophagy with concomitant accumulation of apoptotic bodies, whereas TRPML1 overexpression rescues this phenotype [106]. Furthermore, TRPML1 and PI(3,5)P2 (phosphatidylinositol 3,5-bisphosphate; an activator of TRPML1) signaling is impaired in Nieman-Pick disease (NP) and many other LSDs [107]. Overexpression or increased activity of TRPML1 augments lysosomal $\mathrm{Ca}^{2+}$ release, reverses LEL-Golgi trafficking defects and reduces cholesterol accumulation in NPC cells [108]. Unlike TRPML1, TRPML2 regulates recycling of glycosylphosphatidylinositol-anchored proteins (GPI-APS) through its effect on the small GTPase Arf6 [109], which is implicated in regulating the innate immune response [110]. Mice deficient in both TRPML1 and 3 exhibit growth delay, a phenotype that is not present when only one TRPML isoform is deficient [111]. Collectively, these findings suggest that TRP channels regulate lysosome-dependent processes with therapeutic potential to treat LSDs and lipid storage disease.

\subsection{Two-Pore Channels (TPC)}

Mammals and rodents have two isoforms of TPCs, TPC1 and TPC2, whereas lower vertebrates have the additional isoform TPC3. TPCs span a dual six-transmembrane domain, which exhibits sequence homology with voltage-gated $\mathrm{Na}^{+}$and $\mathrm{Ca}^{2+}$ channels with selective impermeability to $\mathrm{K}^{+}$ ions and permeability to $\mathrm{Ca}^{2+}, \mathrm{Na}^{+}$and $\mathrm{H}^{+}$ions (Figure 2) [112,113]. TPC channels are important for vesicular endocytosis and autophagy function $[114,115]$. TPCs also regulate NAADP (nicotinic acid adenine dinucleotide phosphate)-dependent mobilization of lysosomal luminal $\mathrm{Ca}^{2+}$ stores $[116,117]$. NAADP-dependent lysosomal $\mathrm{Ca}^{2+}$ release is abrogated in MEFs and macrophages isolated from TPC1 or TPC2 knockout mice [117]. Similarly, pancreatic $\beta$-cells isolated from TPC2-knockout mice fail to activate NAADP-dependent cation current [116]. Hearts from TPC2-knockout mice exposed to isoproterenol for 14 days are less hypertrophic, less vulnerable to develop ventricular arrythmias and show improved cardiac function, an observation which also requires functional CaMKII. Additionally, TPC2/NAADP-dependent lysosomal $\mathrm{Ca}^{2+}$ release increases the cytosolic level of $\mathrm{Ca}^{2+}$ released from the ER/SR, suggesting that TPC2/NAADP contributes to the action of $\beta$-adrenoceptor signaling likely by triggering $\mathrm{Ca}^{2+}$-induced $\mathrm{Ca}^{2+}$ release in the heart [118]. These findings support the notion that TPCs play an important role in NAADP-dependent $\mathrm{Ca}^{2+}$ signaling and indicate that TPCs bind to NAADP with high affinity.

\section{3. $P 2 X 4$}

$\mathrm{P} 2 \mathrm{X} 4$ receptor belongs to the family of purinoceptors and is a $\mathrm{Ca}^{2+}$-permeable channel (Figure 2) widely expressed in the central and peripheral nervous system, epithelial cells and smooth muscle cells [119]. P2X4 is primarily localized within the lysosomal compartment, wherein they are targeted via di-leucine and tyrosine motifs and trafficked to the plasma membrane upon lysosome exocytosis [120]. Functionally, P2X4 plays an important role in promoting endo-lysosomal membrane fusion in a $\mathrm{Ca}^{2+} /$ calmodulin-dependent manner [121]. Unlike TRPML and TPC, P2X4 channel is activated during alkalization of the lysosomal lumen but remains inactive in the acidic lysosomal milieu [122,123].

\section{Contact Site Between the Lysosome and other Organelles}

Lysosomes develop membrane contact sites with other organelles to transfer signaling information, to share metabolites and to facilitate ionic homeostasis. This inter-organelle communication, coupled with metabolic changes, profoundly impacts lysosomal function and cellular homeostasis. 


\subsection{Lysosome-ER Contact Site}

Membrane contact sites (MCS) are zones of close apposition ( 30 nM) within cells that are used for inter-organelle communication [124]. Lysosome-ER MCS is implicated in $\mathrm{Ca}^{2+}$ mobilization and signaling, endosome trafficking, maturation, lysosomal biogenesis [125] and positioning [123,126]. Using high-resolution three-dimensional electron microscopy, Friedman et al., demonstrated that ER tubules enclose around endosomes and mobilize, as they remain in contact with microtubules, to facilitate EEs maturation to endo-lysosomes [125]. Notably, 50\% of EEs and 95\% of LEs form a contact site with the ER [125]. Lysosome-ER MCS mobilizes cholesterol (FC) generated within the lysosome via hydrolysis of LDL cholesterol ester to the ER. The concerted action of lysosomal membrane protein (NPC1), ER membrane proteins (VAPA (vesicle-associated membrane protein (VAMP)-associated ER protein A) and VAPB) and lipid-transfer proteins (ORP1L (oxysterol-binding protein-related protein 1L) and ORP5) is necessary for mobilizing FC from the lysosome to the ER (Figure 3A, step 1). ORP5 silencing leads to cholesterol accumulation within the lysosomal lumen, disrupting lysosomal acidification and function $[127,128]$.

The ER and lysosome contact site is also implicated in regulating lysosomal positioning [126,129]. Low cellular cholesterol promotes lysosome-ER MCS formation activating ORP1L, which triggers the anchoring of VAPA with Rab7-RILP (Rab7-interacting protein) (Figure 3A, step 2). Subsequently, perturbation of lysosomal dynein-dynactin interaction induces LEs accumulation within the cell periphery towards the plus end of the microtubule [126]. In contrast, increased cellular cholesterol inhibits ORP1L-VAP interaction and formation of lysosome-ER MSC, enabling dynein-dynactin-dependent mobilization of LEs towards the center of the cell i.e. at the microtubule minus end [126]. In Niemann-Pick disease type C, cholesterol accumulation decreases the movement of lysosomes in both directions, leading to lysosomes aggregating at the perinuclear region [130].

Another important function of the lysosome-ER MCS is the regulation of $\mathrm{Ca}^{2+}$ flux between the two organelles. Lysosomal $\mathrm{Ca}^{2+}$ release mediated by its secondary messenger nicotinic acid adenine dinucleotide phosphate (NAADP), acts as an IP3 receptor agonist that in turn triggers $\mathrm{Ca}^{2+}$ release from the ER (Figure 3A, step 3) [131-135]. The regulation of ER $\mathrm{Ca}^{2+}$ release by the lysosome has been demonstrated in multiple studies [124,136]. Glycyl-L-phenylalanine-2-naphthylamide (GPN) a lysosomotropic agent, evokes lysosomal $\mathrm{Ca}^{2+}$ efflux, which is sufficient to induce a secondary spike in $\mathrm{Ca}^{2+}$ release from the ER into the cytosol in primary-cultured human skin fibroblasts [124,136]. Interestingly, $\mathrm{Ca}^{2+}$ release from the ER can also influence the efflux of lysosomal $\mathrm{Ca}^{2+}$. For instance, in sea urchin egg, $\mathrm{ER} \mathrm{Ca}^{2+}$ release recruits NAADP to the lysosome, activating TPC channels to induce $\mathrm{Ca}^{2+}$ efflux from the lysosome [137]. These findings highlight a bidirectional regulation of $\mathrm{Ca}^{2+}$ signaling occurring between the lysosome and the ER. Proximity ligation assay experiments further indicate a close association between IP3R and LAMP1/Rab7 (marker for late endosome/lysosome), suggesting that bidirectional $\mathrm{Ca}^{2+}$ signaling also requires the formation of lysosome-ER MCS [124,137]. ER-lysosome proximity can be disrupted by inhibiting lysosome acidification. By treating HEK293 cells with v-ATPase inhibitor, interaction between IP3R and LAMP1/Rab7 is reduced, causing the lysosome to redistribute and enlarge, perturbing ER-Ca ${ }^{2+}$ exchange [17]. In contrast, deletion of IP3R isoforms does not affect lysosome-ER proximity, indicating that lysosomal luminal $\mathrm{pH}$ is crucial for the formation of lysosome-ER MCS and for bidirectional regulation of $\mathrm{Ca}^{2+}$ signaling between organelles [17]. 


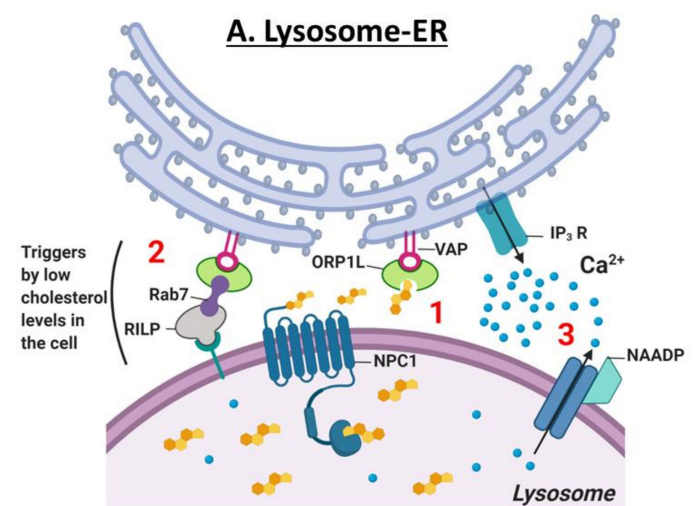

C. Lysosome-Late endosome

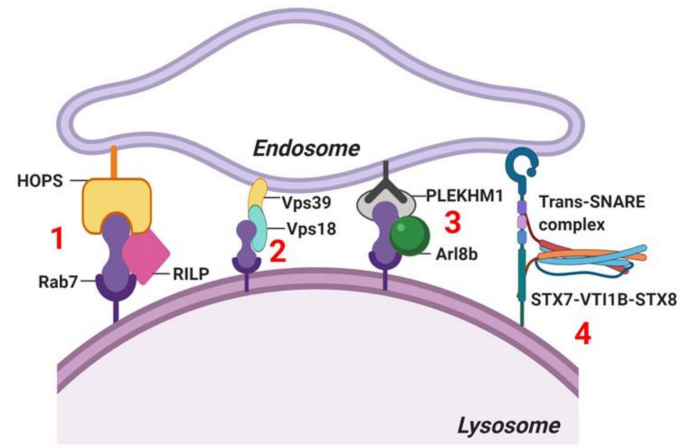

B. Lysosome-Mitochondria

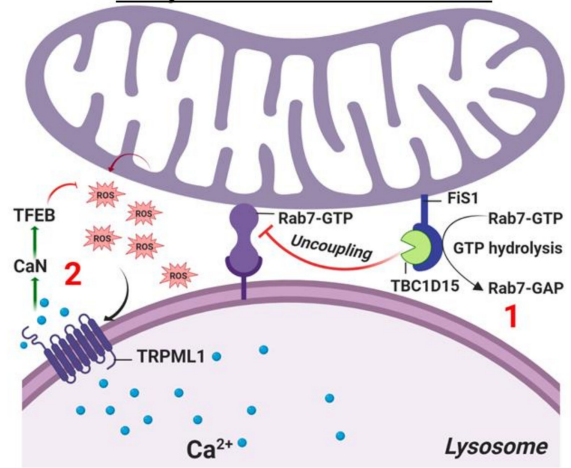

D. Lysosome-Autophagosome

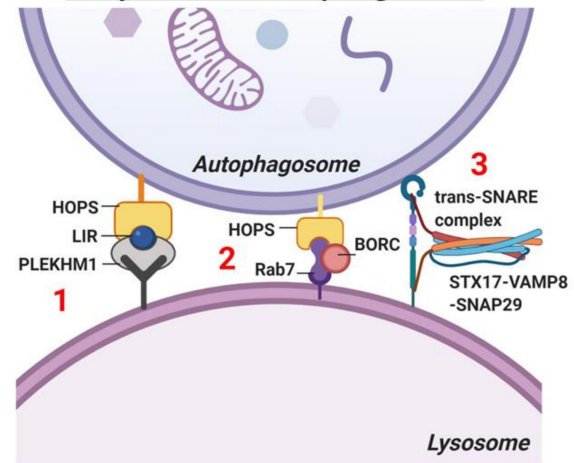

Figure 3. Organellar contact site and fusion with lysosome. (A). Lysosome-ER: Lysosome-ER contact site regulates ER $\mathrm{Ca}^{2+}$ release. (1) Lysosome-ER contact site shuttles free cholesterol from the lysosome to ER via concerted action of lysosomal membrane-localized protein, NPC1 and ER membrane proteins, VAPA (vesicle-associated membrane protein (VAMP)-associated ER protein A) and VAPB and a lipid-transfer protein, ORP1L (oxysterol-binding protein-related protein 1L). (2) Low cellular cholesterol level activates ORP1L, which then triggers the formation of a contact site between ER and lysosomal membrane. ER-resident protein VAP anchors with lysosomal Rab7-RILP (Rab7-interacting protein) to initiate the movement of lysosomes to plus-end or towards the cell periphery. (3) NAADP (nicotinic acid adenine dinucleotide phosphate), a $\mathrm{Ca}^{2+}$ mobilizing entity and IP3 receptor agonist mobilizes lysosomal $\mathrm{Ca}^{2+}$ and facilitates ER $\mathrm{Ca}^{2+}$ release into the cytosol. (B). Lysosome-Mitochondria: Lysosome-mitochondria contract site mediates the bidirectional regulation of lysosome and mitochondria dynamics. (1) Mitochondria forms a contact with the lysosome via lysosomal bound Rab7-GTP. This contact site is disrupted by mitochondrial fission 1 membrane protein, FIS1 and recruits TBC1D15 (TBC1 Domain Family Member 15) which hydrolyzes Rab7-GTP to Rab7-GAP. (2) Lysosomal mucolipin channel, TRPML1 (Transient Receptor Potential Cation Channel, Mucolipin subfamily) governs mitochondria homeostasis by sensing and scavenging mitochondrial ROS (reactive oxygen species). TRPML1 is activated by ROS that induces $\mathrm{Ca}^{2+}$ release from the lysosomal lumen and activates nuclear TFEB translocation in a calcineurin-dependent manner. TFEB induces lysosome biogenesis and autophagy to clear damaged mitochondria and scavenge ROS. (C). Lysosome-Late endosome: The fusion of lysosome and late endosome occurs via tethering processes, which involves; (1) coupling of small GTPase Rab7, Rab7-interacting protein (RIPL) and vacuole protein sorting (HOPS) complex, (2) interaction of Rab7, VPS18 and VPS39 (3) Rab7, Arf-like (Ar18b) and Rab7 effector PLEKHM1 (pleckstrin homology domain-containing protein family member 1 and (4) formation of Trans-SNARE assembly composed of syntaxin-7 (STX7, Qa-SNARE), VTI1B (VPS10 tail interactor-1B, Qb-SNARE) and syntaxin-8 (STX8, Qc-SNARE). (D). Lysosome-autophagosome: The fusion of lysosome and autophagosome occurs via (1) HOPS complex and Rab7 effector protein, PLEKHM1 which binds to HOP via LC3-interacting region (LIR) (2) BLOC-1 related complex (BORC1) that recruits Rab7 and HOPS for tethering and (3) enabling trans-SNARE complex formation of STX17-VAMP8-SNAP29 to induce autophagosome-lysosome fusion. 


\subsection{Lysosome-Mitochondria Contact Site}

Mitochondrial and lysosomal membranes are apart from each other by a distance of $\sim 10 \mathrm{~nm}$, making it ideal for MCS formation between the two organelles [138,139]. Approximately $15 \%$ of lysosomes form a contact site with mitochondria [138]. Recently, Wong et al., demonstrated that lysosomes and mitochondria form a stable MCS, which is induced by the lysosomal GTP-bound Rab7 protein, highlighting the bidirectional regulation of lysosome and mitochondrial dynamics [139]. Alternately, uncoupling of lysosome-mitochondria MCS is promoted by hydrolysis of Rab7-GTP driven by the Rab7-GAP protein, TBC1D15 (TBC1 Domain Family Member 15), which is recruited by the mitochondrial protein Fis1 (mitochondrial fission 1 protein) [139]. However, in HeLa cells, mutation in Rab7, Fis1 or TBC1D15 prevents the recruitment of TBC1D15 to the mitochondria, resulting in an increase in the duration of mitochondria-lysosome contact site, causing accumulation of enlarged lysosomes and impairment in mitochondrial fission events (Figure 3B, step 1) [139]. However, the lysosome-mitochondria MCS formation was not prevented by the penta knockout (p62, NDP52, OPTN, NBR1 and TAX1BP1) of mitophagy markers in Hela cells, suggesting that MCS formation is independent of the process of mitophagy [138].

Both lysosome function and lysosomal $\mathrm{Ca}^{2+}$ are critical to regulate mitochondrial function and homeostasis $[16,105,139]$. The TRPML1 channel located on the lysosome, releases $\mathrm{Ca}^{2+}$ in response to increases in mitochondrial reactive oxygen species (ROS). To scavenge ROS and damaged mitochondria, lysosome biogenesis and autophagy is increased by ROS-dependent activation of calcineurin and ensuing nuclear translocation of TFEB (Figure 3B, step 2) [105]. Prior study demonstrates that deficiency in mitochondrial function in $\mathrm{CD}^{+} \mathrm{T}$ lymphocytes by genetic deletion of mitochondrial transcription factor A (Tfam), results in impaired lysosome function and autophagy [140]. Using both an in vitro model and an in vivo mouse model of respiratory chain dysfunction, it was shown that acute mitochondrial stress increases lysosome biogenesis via an AMPK-TFEB/MITF-dependent pathway [141]. However, it is unclear whether the mutual relationship between lysosome and mitochondria to regulate biogenesis, metabolism and function requires the formation of lysosome-mitochondria membrane contact site.

\section{Lysosome Fusion and Fission Events}

\subsection{Late Endosome-Lysosome-Autophagosome Fusion}

Macromolecules are transported via secretory vesicles, or an endocytic, autophagic or phagocytic pathway for degradation. Since LEs and lysosomes are located near the microtubule-organizing center, the bulk of lysosome-endosome fusion occurs in the juxtanuclear region. Organelle fusion ensues via tethering processes when two organelles form a contact site over a distance of $\sim 25 \mathrm{~nm}$ [142]. Tethering of lysosomes and endosomes requires the small GTPase Rab7, which interacts with RILP (Rab7-interacting protein) and recruits HOPS (mammalian homotypic fusion and vacuole protein sorting ) complex (Figure 3C, step 1) [143,144]. Notably, Rab7, coupled with VPS18 and VPS39, also promotes tethering of LEs and lysosomes (Figure 3C, step 2). Alternatively, overexpression or silencing of either Rab7, VPS18 or VPS39 in HeLa cells results in organelle clustering and organelle dispersion, respectively [145-147]. In addition to the small GTPase Rab7, formation of the HOPS complex assembly on a lysosome requires Arf-like8b (Arl8b) [148]. Indeed, co-binding of Rab7 and Arl8b to Rab7 effector PLEKHM1 (pleckstrin homology domain-containing protein family member 1) induces clustering and heterotypic fusion of LEs-lysosomes (Figure 3C, step 3) $[144,148,149]$. Fusion of lysosomes-LEs also requires Trans-SNARE (soluble N-ethylmaleimide-sensitive factor attachment protein receptor) assembly, composed of three clustered Q-SNARE (Qa, Qb and Qc) elements, which interact with R-SNARE through their N-terminal end of the SNARE motif [150]. Notably, synaptotagmin I and complexin proteins exert control over the Trans-SNARE complex. Synaptotagmin I triggers $\mathrm{Ca}^{2+}$-dependent fusion of organelles by using its two $\mathrm{Ca}^{2+}$-binding $\mathrm{C} 2$ domains, while complexin binds to the surface of the SNARE complex in a $\mathrm{Ca}^{2+}$-dependent manner to regulate organelle fusion [151]. Furthermore, 
antibody-based function-blocking experiments provided evidence that Q-SNARE such as syntaxin-7 (Qa-SNARE), VTI1B (VPS10 tail interactor-1B, Qb-SNARE) and syntaxin-8 (Qc-SNARE) are required for endosome-lysosome heterotypic fusion. R-SNARE requires VAMP7 (vesicle-associated membrane proteins) and VAMP8 for both heterotypic and homotypic (fusion of lysosomes) events (Figure 3C, step 4) [82,152].

Lysosomes also fuse with autophagosomes, which is critical for macromolecule degradation via formation of autolysosomes [153]. A well-coordinated transport of lysosomes and autophagosomes to the perinuclear region of the cell is required for effective fusion between two organelles [154-156]. During starvation, an increase in intracellular $\mathrm{pH}$ causes mobilization of autophagosomes and lysosomes via microtubules to the perinuclear area [85,157]. Both HOPS complex and Rab7 effector protein PLEKHM1 integrate endocytic and autophagic pathways at the lysosomal membrane [158,159]. At least in HEK293 cells, the interaction with autophagosomal membranes is facilitated by PLEKHM1 binding to HOPS via the LC3-interacting region (LIR) (Figure 3D, step 1) [159]. Silencing PLEKHM1 in Hela and HEK293 cells failed to activate autophagy upon mTOR inhibition, suggesting that PLEKHM1 is crucial for autophagosome-lysosome fusion $[158,159]$. Similar to PLEKHM1, BLOC-1 related complex (BORC1) is implicated in autophagosome-lysosome fusion [160]. In non-neuronal cells, BORC1 facilitates recruitment of Rab7-HOPS (Figure 3D, step 2) for tethering and enables Trans-SNARE complex formation of STX17-VAMP8-SNAP29 to induce autophagosome-lysosome fusion (Figure 3D, step 3), whereas knockdown of BORC disrupts autophagosome-lysosome fusion [160]. Interestingly, Nguyen et al., demonstrated that autophagosome formation and selective sequestration of mitochondria in HeLa cells is regulated by GABARAP but not STX17 [161]. Additionally, cytosolic $\mathrm{Ca}^{2+}$ augments lysosomal fusion to the plasma membrane to trigger lysosome exocytosis, which is described later in the review.

\subsection{Lysosomal Exocytosis (Fusion of Lysosomes with the Plasma Membrane)}

Lysosomes also regulate secretory vesicles through lysosome exocytosis. Exocytosis of the lysosome involves two main steps: (1) lysosomal movement to the cell periphery for plasma membrane (PM) fusion, and (2) exocytosis of the luminal content of the lysosome into the extracellular milieu. Lysosomal exocytosis is paramount for various cellular physiological processes such as PM repair (PMR), immune response, bone resorption and cell signaling [162]. PM integrity is lost upon injury, resulting in unlimited exchange of intra- and extra-cellular components triggering cell death; thus, PM repair is crucial for the maintenance of cellular homeostasis. Upon PM injury, cytoskeletal and motor proteins induce trafficking of lysosomes to the damaged PM at the cell periphery, wherein lysosomes fuse directly with the PM and empty their content into the extracellular space [107]. PM damage induced by exposing Hela cells to mechanical stress, triggers the colocalization of the motor protein KIF5B (Kinesin5 subfamily member) with LAMP1-positive lysosomes, which are then mobilized towards the cell periphery (Figure 4, step 1) [163]. Depletion of KIF5B in Hela cells causes lysosome immobilization and peripheral lysosome aggregation, signifying that motor proteins possess an important role in lysosomal mobilization during exocytosis [163].

Amongst the different ways cells adapt to various effector stimuli is a cell's capacity to sense increases in intracellular $\mathrm{Ca}^{2+}$ level and respond by triggering lysosomal exocytosis (Figure 4, step 2) [164]. The rate of increase in $\mathrm{Ca}^{2+}$ influx following PM damage is sensed by synaptotagmin-VII (Syt-VII) at the lysosomal membrane (Figure 4, step 3) [164]. Subsequently, Syt-VII interacts with Trans-SNARE complex on the PM, which is formed by the interaction of lysosome-localized VAMP7 (Vesicle-associated membrane protein 7) with syntaxin-4 and SNAP23 (synaptosome-associated protein $23 \mathrm{kDa}$ ). To facilitate fusion, trans-SNARE complex brings lysosomes into close proximity with the PM (Figure 4, step 4) [165]. Indeed, treatment with ionomycin suppresses lysosome exocytosis in embryonic fibroblasts isolated from Syt-VII KO mice expressing negative-dominant VAMP7 construct, [165], suggesting that Trans-SNARE complex and Syt-VII exert important functions in membrane fusion and exocytosis. Following membrane fusion, exocytosis causes efflux of the lysosomal enzyme 
sphingomyelinase (aSMase), which converts sphingomyelin into ceramide on the PM (Figure 4, step 5) [166]. This results in an inward curvature of the PM to facilitate endocytosis-mediated removal and resealing of the damaged PM (Figure 4, step 6) [166,167], an effect impaired in cells deficient in aSMase. Although lysosomal exocytosis is permissible, the ability to facilitate PM repair through endocytosis is suppressed in aSMase deficient cells [166,167], suggesting that aSMase is critical for lesion internalization and repair.

TRPML1 (mucolipin-1), a Ca ${ }^{2+}$-permeable non-selective cation channel is a driver of lysosome exocytosis $[164,168]$. MCOLN1 gene (encodes mucolipin-1, MLN1) mutations cause Mucolipidosis type IV (MLIV) characterized by late endosome/lysosome accumulation. Dermal fibroblasts from MLIV patients display decreased TRPML1 channel activity and impaired lysosome exocytosis as measured by the rate of NAG ( $N$-acetyl- $\beta$-D-glucosaminidase) enzyme release following ionomycin treatment, effects which are rescued by TRPML1 overexpression [168]. Collectively, these findings suggest that MLN1 possesses an important role in regulating lysosome exocytosis.

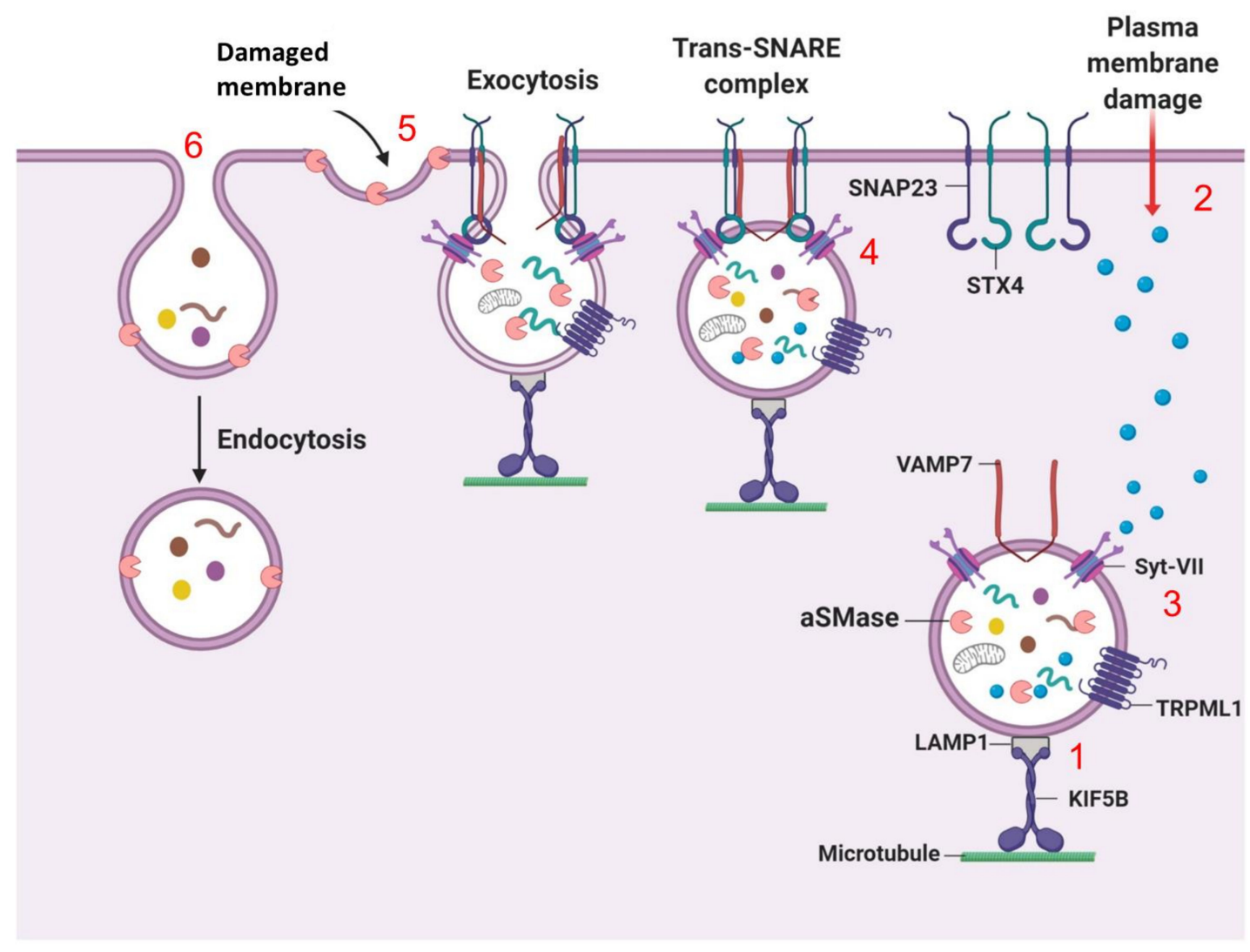

Figure 4. Lysosome exocytosis-dependent plasma membrane repair. Upon damage to the PM, (1) lysosomes are translocated to the cell periphery via cytoskeleton and motor protein, Kinesin 5 subfamily member KIF5B, which is bound to LAMP1 on the lysosomal membrane. (2) Injury to the PM can lead to an influx of $\mathrm{Ca}^{2+}$ in cells, which is then (3) sensed by $\mathrm{Ca}^{2+}$ sensor, Syt-VII (synaptotagmin-VII) on the lysosomal membrane and triggers a repair mechanism. (4) Subsequently, exocytosis is initiated by the lysosomal membrane localized VAMP7 (vesicle-associated membrane protein 7) that forms a Trans-SNARE complex with syntaxin-4 and SNAP23 (synaptosome-associated protein $23 \mathrm{kDa}$ ) on the PM. Trans-SNARE complex brings the lysosome in a close proximity to the PM to initiate the fusion of lysosome and PM. (5) The fusion of lysosome and PM triggers an efflux of lysosomal enzyme aSMase (sphingomyelinase), which is then retain on the PM to convert sphingomyelin into ceramide, (6) leading to an inward configuration of the PM to facilitate endocytosis-dependent removal and restoration of damaged PM. 


\subsection{Lysosome Fission}

Lysosome fission is crucial for maintaining steady-state levels of lysosome number and size [169,170]. Lysosome fission involves vesiculation, tubulation and "kiss-and-run" events [13]. Proteins involved in the vesiculation process include an outer-coat protein clathrin, an inner-coat adaptor protein known as AP, and the motor protein dynamin 1 [169]. Initiation of vesiculation occurs via cargo sorting, a process that requires binding of adaptor protein (AP) complex to the lysosomal membrane. Subsequently, clathrin and its structural protein scaffolds, sec 13/31 COPII subcomplex, curve and deform the membrane [169]. These steps culminate in activation of scission machinery proteins such as dynamin 1, a GTPase or AAA-ATPase Vps4 of ESCRT-III complex or BAR (brefeldin A ADP-ribosylated substrate) domain protein scaffold, catalyzing the membrane fission by dissociating vesicles from the lysosomal membrane (Figure 5A) [169,170].
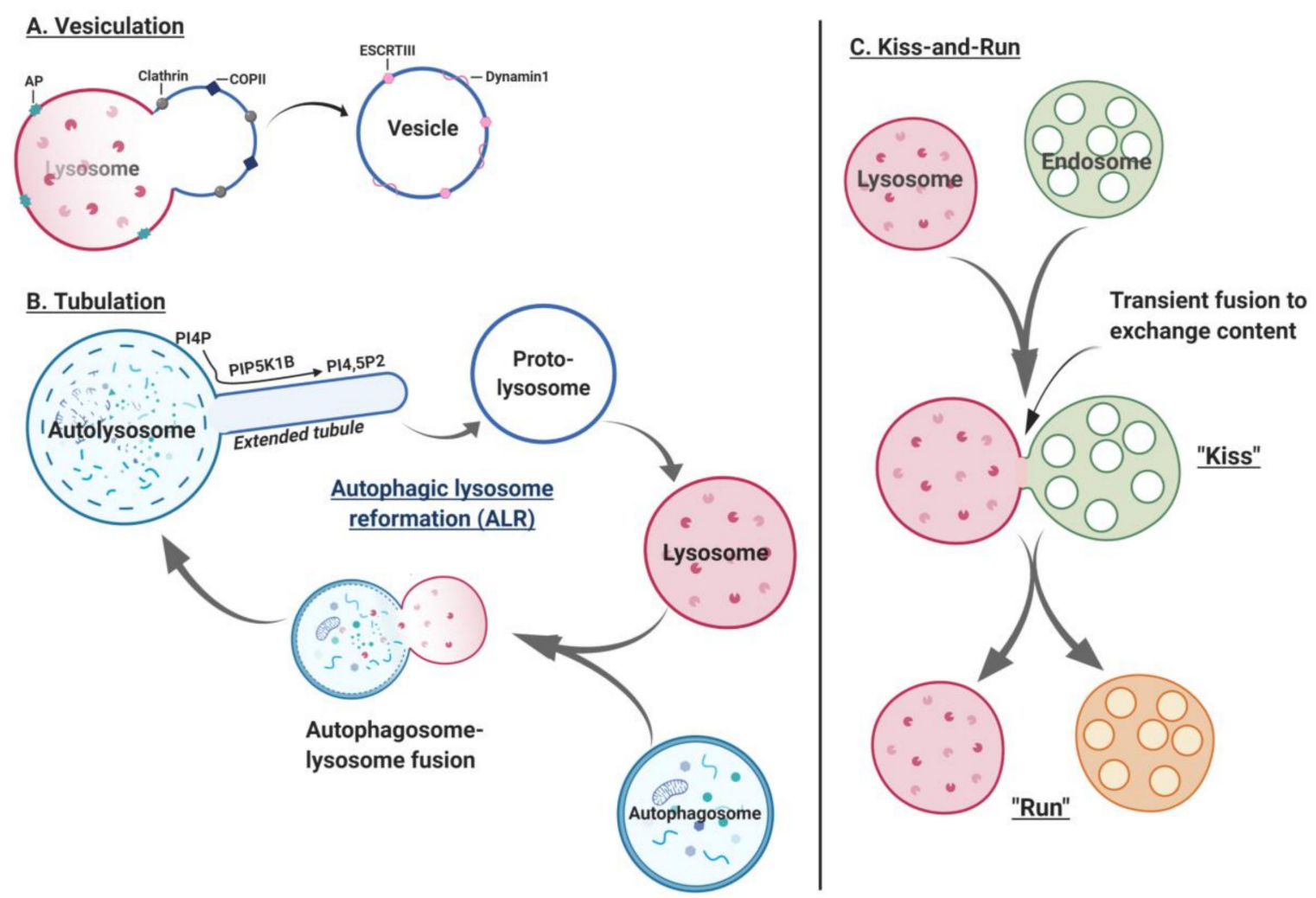

Figure 5. Lysosome fission. Lysosome fission involves, vesiculation process (A) is initiated by inner-coat adaptor protein-dependent cargo sorting, followed by membrane deformation mediated by clathrin and structural scaffold of COPII subcomplex. Subsequently, scission machinery including dynamin 1 and ESCRT-III catalyzes the membrane fission and dissociates vesicle from the lysosomal membrane. The process of tubulation (B) is best described by autophagic lysosome reformation (ALR), wherein proto-lysosomes derived from ALs, mature into functional lysosomes known as lysosome reformation. These matured lysosomes then subsequently fuse with autophagosomes to form ALs and initiate the cycle of lysosome reformation. The final event of lysosome fission is kiss-and-run (C), which involves the fusion of lysosomes and late endosomes. The transient interaction ("Kiss") between lysosome and LEs allows the exchange of content, followed by separation of the lysosome ("Run").

After vesiculation, the process of tubulation recycles and reforms lysosomes via tubular extrusion. Tubulation is initiated by the coat protein clathrin, which deforms and curves the membrane to form the tip of the nascent tubule. During periods of prolonged starvation, initial decline of cellular lysosome content occurs concomitantly with autolysosome (AL) formation, followed by de novo replenishment of the lysosomal pool. This process of de novo formation of lysosomes is termed as autophagic lysosomal 
reformation (ALR) [171]. ALR theory best describes the lysosome tubulation process. Rat kidney cells subjected to $4 \mathrm{~h}$ of nutrient deprivation stained positive for LAMP1 (marker for lysosome) and LC3 (marker for AL), whereas cells starved beyond $12 \mathrm{~h}$ stained positive only for LAMP1 and not LC3 [172]. Therefore, acute starvation augments AL content, whereas chronic starvation restores lysosome content to levels observed before starvation [172]. Furthermore, "proto-lysosomes", which are non-acidified and empty extended tubular structures, were observed on LAMP1-YFP positive ALs by 8 hof starvation [172]. However, by 12 hof starvation, proto-lysosomes mature into functional lysosomes by acquiring acidity and degradative capacity via the process of ALR (Figure 5B) [172].

Co-localization studies and clathrin-knockdown approaches demonstrated that clathrin recruitment is increased $12 \mathrm{~h}$ post starvation to regulate ALR [173]. Proteomic analysis and SAMCell-RNAi screening identified clathrin-heavy chain and phosphatidylinositol-4-phosphate 5-kinase (PIP5K1B) as candidate protein regulating ALR [173]. Furthermore, PIP5K1B converts PI4P (phosphatidylinositol-4-phosphate) into PI4,5P2 (phosphatidylinositol-4,5-biphosphate) on ALs to trigger clathrin recruitment via adaptor protein AP2 [172-174]. During acute starvation, PIP5K1B silencing leads to enlargement in LC3-CFP- and LAMP1-YFP-positive ALs impairing clathrin-dependent tubule reformation and ALR $[172,173]$. Furthermore, during prolonged starvation, amino acid transport from ALs to the cytoplasm restores mTOR activity and inhibits autophagy with concomitant generation of LAMP-1-positive proto-lysosomal tubules extruding from the ALs [172]. Interestingly, impaired mTOR reactivation and loss of ALR is observed in fibroblasts from patients with Pompe and Niemann-Pick disease [172]. These data indicate that mTOR couples cellular nutrient status to autophagic functioning through its regulation on ALR and lysosome numbers.

Lysosomal fission events culminate in the "kiss-and-run" fusion process. Initially, fusion of autophagosomes and late endosome/lysosome occurs to generate a fully matured, hybrid organelle. However, multiple organelles fuse frequently to exchange their content despite being separate vesicles, denoted as a "kiss-and-run" event [175]. Indeed, Bright et al., elegantly demonstrated the kiss-and-run content mixing model in a living cell by labeling endosomes and lysosomes with Oregon green 488 and rhodamine dye, respectively [175]. A transient interaction occurs between green-endosome and red-lysosome with progressively augmented red-over-green fluorescence intensity, indicating a "kissing" event that eventually terminates in separation of a red-lysosome, highlighting a kiss-and-run delivery of red fluorescence independent of direct fusion (Figure 5C) [175].

\section{Lysosome Localization and Movement}

Intracytoplasmic movement of the lysosome is critical for executing processes such as lysosome biogenesis, protein quality control and metabolism to ensure cellular homeostasis. Altered lysosomal acidification [157,176], misfolded protein aggregate formation [177] and cellular nutrient status [178] perturb lysosome positioning and motility. During fed conditions, lysosomes are peripherally localized, whereas after nutrient depletion, lysosomes migrate towards peri-nuclear regions to facilitate autophagosome-lysosome fusion. The mobilization of lysosomes from the cell periphery towards the perinuclear region is termed "retrograde movement", while movement of lysosomes from the perinuclear area towards the cell periphery is termed as "anterograde movement" [179-181]. Lysosomal movement in the cell is assisted by cytoplasmic dynein motor proteins and activator protein dynactin, and with kinesin motor proteins [179-181]. Lysosomes exhibit bidirectional movement along microtubular platforms, which are regulated by microtubule motor proteins. Dynein motor proteins, with associated dynactin proteins, allow retrograde movement of lysosomes from the plus end to the minus end of microtubules [143,182]. Rab7 GTPase and its downstream target RILP are obligatory for dynein-dynactin recruitment to the lysosome and for transport of lysosomes to the central region of the cell (Figure 6, step 1) [143]. Moreover, TBC1D15 (GTPase-activating protein, GAPs) and TBC1D2 [181,183] govern Rab7-dependent recruitment of dynein-dynactin on the lysosome. Kinesin superfamily (KIF) proteins, which includes kinesin-1 (KIF5A, KIF5B and KIF5C) [184], kinesin-2 (KIF3) [185] and kinesin-3 (KIF1A, KIF1B) [186], trigger the anterograde movement of the lysosome 
from the minus end to the plus end along the microtubule and ultimately regulate lysosome positioning (Figure 6, step 2) [179-181]. Similarly, BLOC-1-related complex (BORC), a multicomplex protein consisting of eight subunits, is indispensable for lysosome positioning and movement. BLOC-1 interacts with the lysosomal membrane through Arf-like small GTPase Arl8 (Figure 6, step 3) [187]. Subsequently, a signaling cascade is initiated via Kinesin-interacting protein (SKIP) to promote lysosome migration towards the cell periphery [187].

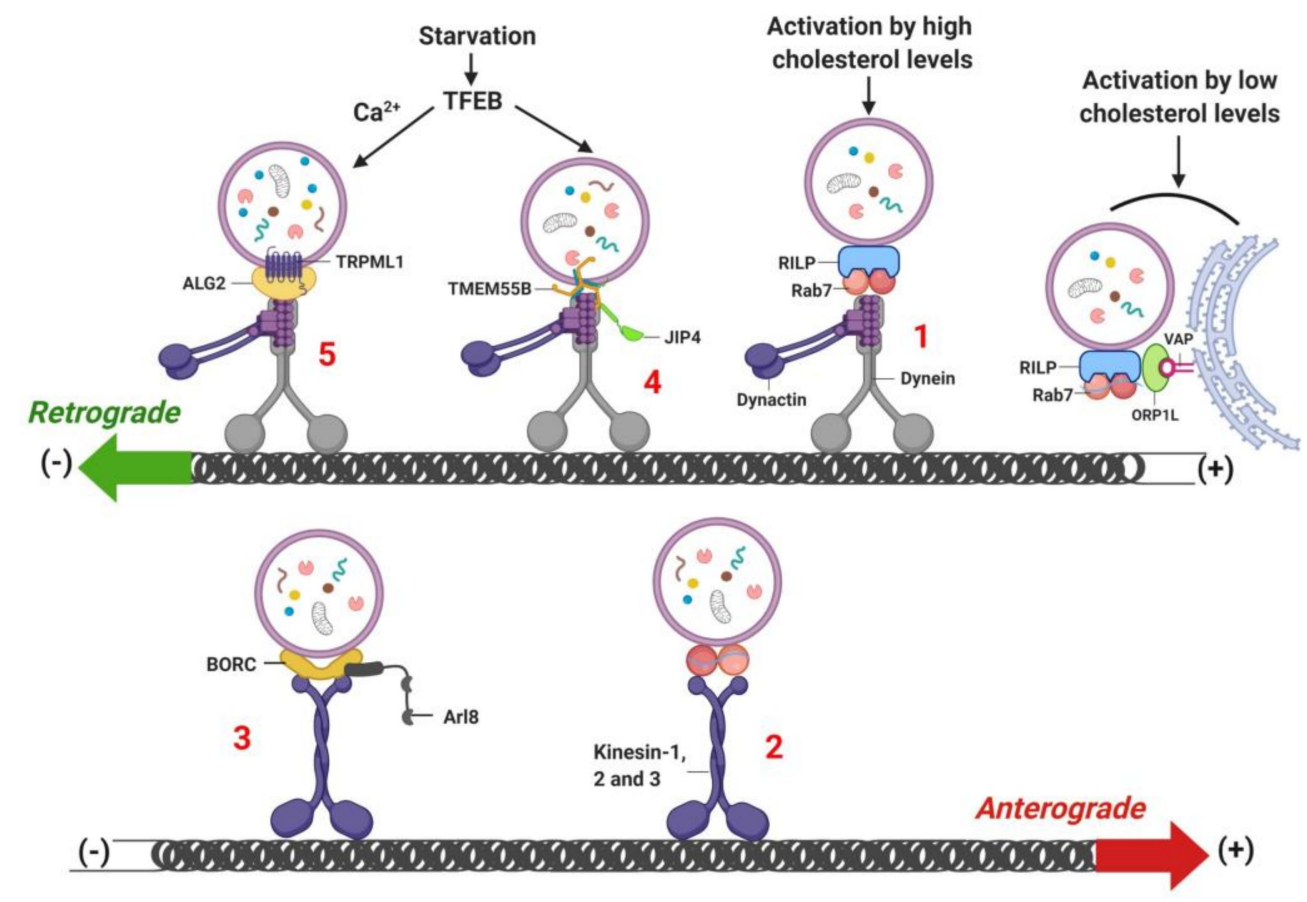

Figure 6. Retrograde- and anterograde-dependent lysosome mobilization. Lysosomes move from the cell periphery towards the perinuclear region in a retrograde manner. (1) The retrograde movement of the lysosome is initiated by RILP-Rab7-dependent recruitment and activation of dynein-dynactin, enabling the transport of lysosomes to minus-end direction. (2) While anterograde movement transport lysosomes from the perinuclear to the cell periphery, which requires kinesin-1, 2 and 3 motor proteins. (3) Anterograde movement of lysosomes also requires BLOC-1-related complex (BORC)-dependent recruitment of Arl8, which activates the kinesin proteins. (4) and (5) starvation-induced activation of TFEB increases the transcription of TRPML1 and TMEM55B to trigger lysosome mobilization in a retrograde manner via interaction with ALG2 (an EF-hand-containing protein, serve as lysosomal $\mathrm{Ca}^{2+}$ sensor) and JIP4 (C-Jun-amino-terminal kinase-interacting protein 4), respectively. Low cellular cholesterol levels restrict lysosomes at the plus end, which is mediated by the interaction between lysosomal RILP and Rab7 with VAP and ORP1L on ER membrane.

Intraluminal acidification of the lysosome is dependent on the intracellular localization and movement of the lysosome $[85,176]$. Quantitative ratiometric fluorescence microscopy reveals that peripheral lysosomes are more alkaline compared to centrally localized lysosomes. Peripheral lysosomes exhibit higher proton leakage and reduced vATPase activity compared to the centrally-localized lysosomes [85]. Furthermore, peripheral lysosomes display increased Arl8b expression and recruitment of kinesin-1 on their membrane, whereas Rab7 abundance and recruitment of RILP are reduced [85]. On the contrary, lysosomes at the perinuclear region exhibit higher vATPase activity and increase in Rab7-dependent recruitment of RIPL on lysosomes [85]. Due to higher vATPase activity, perinuclear lysosomes are preferentially used for proteolytic degradation [85]. Together, these findings suggest that lysosome localization influences vATPase activity, which is crucial for maintaining intraluminal $\mathrm{pH}$. 
Cellular nutrient status also influences lysosome localization and motility to regulate mTORC1 activity. During nutrient-rich conditions, mTORC1 is activated on peripheral lysosomes to ensure close proximity to signaling receptors at the cell surface [178]. Alternatively, starvation represses mTORC1 activity and induces perinuclear clustering of lysosomes due to changes in luminal $\mathrm{pH}$ of the lysosome, which in turn is critical for autophagosome formation and autophagosome-lysosome fusion [178]. Starvation induces transcription of genes encoding for TRPML1 and TMEM55B by activating TFEB and TFE3. Retrograde mobilization of the lysosome is induced in a dynein-dynactin manner by TRPML1 and TMEM55B, which interact with C-Jun-amino-terminal kinase-interacting protein 4 (JIP4) (Figure 6, step 4) [188]. A recent study demonstrated that TRPML1 activation induces biogenesis of autophagic vesicles by generating phosphatidylinositol 3-phosphate (PI3P) and recruiting PI3P-binding proteins to the nascent phagophore [189]. TRPML1 activity is also required for $\mathrm{Ca}^{2+}$-dependent centripetal transport of the lysosome towards the perinuclear region in HeLa cells and Cos1 cells, an effect independent of the Rab7-RIPL pathway [78]. Furthermore, TRPML1 activity requires the interaction between ALG-2 (an EF-hand-containing protein, serve as lysosomal $\mathrm{Ca}^{2+}$ sensor) and dynein-dynactin for retrograde mobilization of the lysosome (Figure 6, step 5) [78]. Notably, increases in phagophore formation by TRPML1 requires signaling by calcium-dependent kinase CaMKK $\beta$ and AMPK, which activates ULK1 and VPS34 autophagic protein complexes[189]. Indeed, mouse fibroblasts treated with $\mathrm{Ca}^{2+}$ chelator BAPTA-AM, demonstrate significantly reduced retrograde and anterograde lysosomal motility, suggesting that $\mathrm{Ca}^{2+}$ is important for regulating lysosome positioning and movement [78].

\section{Lysosome-Dependent Protein Degradation}

Lysosomes contain luminal proteases, lipases, glycosidases and nucleases that degrade intracellular and extracellular macromolecules via autophagy [190]. To maintain cellular energy balance and organelle homeostasis, lysosomal autophagy (self-eating/digestion) degrades and recycles both shortand long-lived proteins, protein aggregates, mitochondria (mitophagy) [191], nuclei (nucleophagy) [71], endoplasmic reticulum (reticulopathy) [192], lipid droplets (lipophagy) [190], and peroxisomes (pexophagy) [193]. Two primary types of autophagy are described in mammalian cells, macroautophagy and chaperone-mediated autophagy (CMA). A less characterized type of autophagy is microautophagy (MIA) involving pinocytosis of cytosolic regions surrounding lysosomes thereby engulfing and degrading cytosolic cargo.

\subsection{Macroautophagy}

Macroautophagy occurs within an ER-derived double membrane-bound organelle, known as an autophagosome, which allows the bulk delivery of proteins and organelle cargo to lysosomes for proteolysis. Autophagy related gene (Atg) proteins organize and control various steps of macroautophagy [194,195]. Macroautophagy is initiated through the formation of an ER-derived pre-autophagosome, containing partially selected bulk sequestration of protein cargo and organelles. Pre-autophagosome assembly requires the functional class III phosphatidylinositol-3-kinase (PI3K) complex [196,197]. Elongation and maturation of the pre-autophagosome requires the ubiquitin-like conjugation system. Autophagosome closure and maturation is governed by the lipidation of microtubule-associated protein 1 light chain 3 (LC3I) to form LC3II. Subsequently, autophagosomes fuse with lysosomes forming autolysosomes, wherein lysosomal proteases degrade intra-autophagosomal content [198]. In this section, we have only superficially addressed different types of autophagic processes as they are comprehensively reviewed elsewhere $[195,199]$.

\subsection{Lipophagy, Mitophagy and Lysophagy}

Lysosomal autophagy also plays an important role in breaking down lipid droplets via a process referred to as "lipophagy" [200]. Lipophagy was first described in hepatocytes and is indispensable for TAG breakdown as Atg7 $7^{-1-}$ mice displayed hepatic TG accumulation [201,202]. In addition to lipophagy, mitophagy ensures mitochondrial quality control by degrading dysfunctional mitochondria and 
maintaining functionally-active mitochondria [203-205]. Dysfunctional mitochondria that are unable to handle ROS overload are targeted for mitophagy by a PTEN-induced putative kinase 1 (PINK1)-Parkin mediated mechanism [206]. Specifically, PINK1 protein content is increased on the mitochondrial outer membrane, which signals Parkin-mediated ubiquitination of PINK1 molecule [206]. Ubiquitinated PINK1 molecules are targeted by ubiquitin cargo receptors p62/SQSTM1 and NBR1 [207,208]. Similar to mitochondria, damaged lysosomes are also subjected to repair or clearance albeit with assistance from ESCRT machinery-dependent sorting complex. The process of degrading damaged lysosomes via selective macroautophagy is termed as "lysophagy" [209-211]. Impaired lysosomal homeostasis is observed when lysosomes are damaged due to increased lysosomal membrane permeabilization, or lysosomal stress induced by lysosomotrophic agents [212,213]. Upon injury, damaged lysosomes efflux their luminal $\mathrm{Ca}^{2+}$ stores and activate the lipid-binding activity of the ESCRT complex, which is essential to repair lysosomes by reacidifying the lysosomal lumen and replenishing the lysosomal hydrolases [210]. Prior studies suggest that damaged lysosomes expose luminal glycan to the cytosol, which is sensed by galectin-3 and recruits E3 ubiquitin ligase TRIM16 to trigger ubiquitination of the damaged lysosomes $[209,214]$. Following the ubiquitination of lysosomes, the autophagic machinery is activated to initiate lysophagy (Figure 7) [209,214].

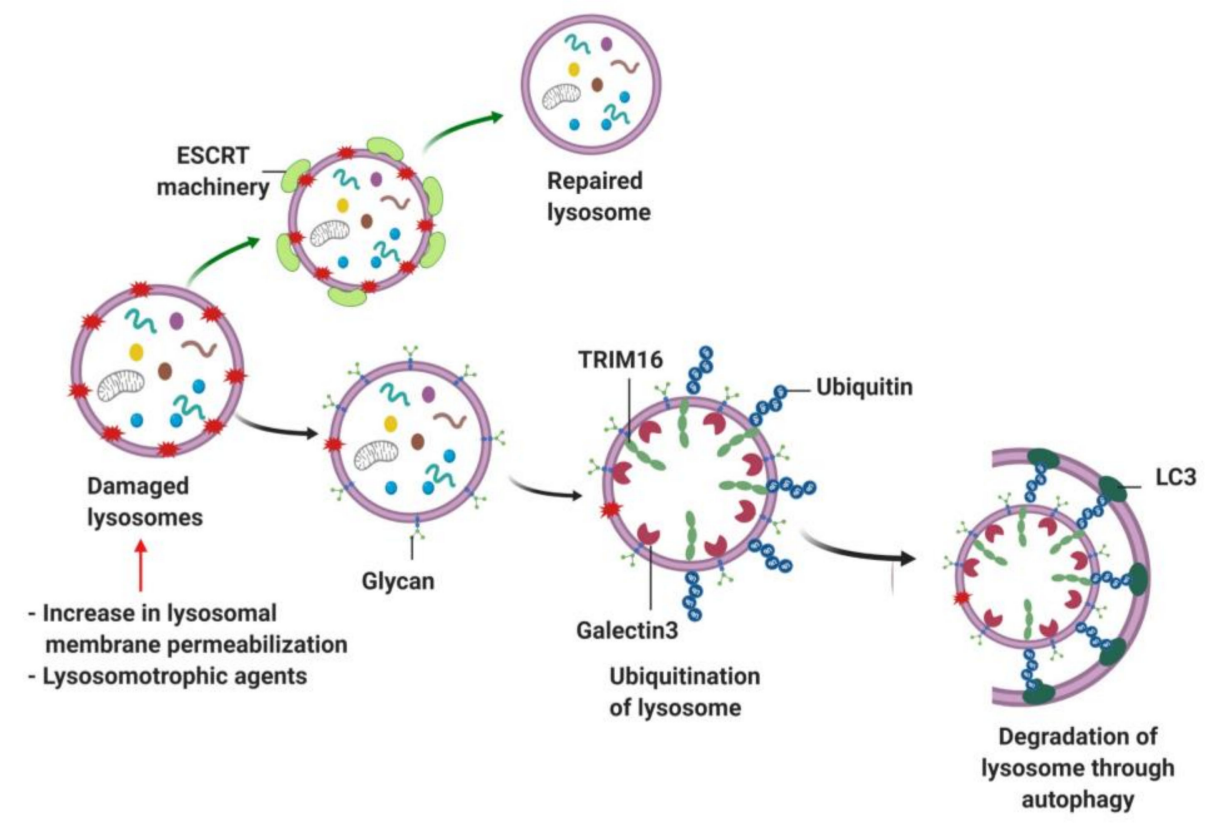

Figure 7. Lysosome repair by lysophagy. Damaged lysosomes can efflux luminal $\mathrm{Ca}^{2+}$ stores and activate ESCRT machinery component to repair lysosome by restoring lysosomal integrity. However, lysosomes are subjected to degradation when damaged. Severely damaged lysosomes can expose luminal glycan to the cytosol, which is sensed by galectin-3 to trigger lysosome ubiquitination via TRIM16. Following lysosome ubiquitination, lysophagy initiates lysosomal degradation.

\subsection{Chaperone-Mediated Autophagy (CMA)}

CMA is initiated $\sim 10 \mathrm{~h}$ after starvation and, unlike macroautophagy, promotes selective protein degradation $[215,216]$. CMA targets $\sim 35 \%$ of soluble cytosolic proteins, which harbor a KFERQ (composed of sequence of amino acids includes lysine $(\mathrm{K})$, phenylalanine $(\mathrm{F})$, glutamic acid $(\mathrm{E})$, arginine (R) and glutamine (Q)) consensus motif, for lysosomal degradation [215]. Cytosolic chaperones, heat-shock cognate protein of $70 \mathrm{kDa}$ (hsc70) and heat shock protein 90 (Hsp90) recognize the KFERQ motif and deliver targeted proteins to the lysosomal surface for binding to lysosome-associated membrane protein-2A (LAMP-2A) [217,218]. Upon binding to LAMP-2A, the substrate protein is unfolded, translocated and rapidly degraded within the lysosomal lumen. Given that the proteins undergoing degradation through CMA exhibit diverse roles in a myriad of intracellular processes, it is 
plausible that changes in LAMP-2A function and lysosomal biogenesis could have a significant impact on degradation of CMA-targeted proteins and lead to significant impacts on cellular metabolism and function.

\subsection{Microautophagy}

Microautophagy is a process wherein direct invagination of lysosomes facilitates intracellular degradation of protein and organelle cargo. New studies have identified the role of microautophagy in processing cargos through peroxisomes (micropexophagy) [219], mitochondria (micromitophagy) [220] and lipid droplets (microlipophagy) [221].

\section{Lysosome Dysfunction in Diseases}

Lysosomal storage disorders (LSDs) are a group of disorders caused by inherited mutations of genes involved in lysosomal function, leading to macromolecule accumulation within lysosomes. Additionally, defects in lysosome function have been identified in other conditions including cancer, cardiovascular disease and metabolic disorders.

\subsection{Lysosomal Storage Disorder (LSDs)}

LSDs are a family of 70 rare monogenic diseases that are clinically exist during infancy or childhood. LSDs affect 1 in 7700 live births [222]. Most LSDs represent mutations in the genes encoding lysosomal hydrolases, lysosomal membrane proteins, proteins involved in trafficking, and non-lysosomal proteins. LSDs are often associated with early-onset neurodegeneration and neurological sequelae are often triggered by undigested lysosomal macromolecules [4]. Depending on the accumulation of substrates, LSDs exhibit distinct phenotypes. For instance, a mutation in lysosomal enzyme $\beta$-glucocerebrosidase (GBA gene) causes Gaucher disease, characterized by organomegaly and cytopenia [223]. Deficiency in $\beta$-galactosidase (encoded by HEXA) and $\beta$-hexosaminidase (encoded by HEXB) result in the accumulation of gangliosides, characterized by severe neurological defects. Similarly, loss of function of HEX subunit A or B causes Tay-Sachs or Sandhoff disease [224]. Pompe disease or glycogen storage disease type II is characterized by lysosomal glycogen accumulation, caused by a deficiency of $\alpha$-glucosidase enzyme (encoded by GAA gene) [225] resulting in cardiac and respiratory failure [226,227]. Similarly, defects in lysosomal membrane proteins such as NPC1, LAMP2 and MCOLN1 cause Niemann-Pick type C (NPC), Danon and Mucolipidosis type IV (MLIV) diseases [228,229], respectively. NPC disease is caused due to a mutation in either NPC1 or NPC2 gene, resulting in the intralysosomal accumulation of cholesterol, sphingolipid, glycosphingolipid, sphingosine and sphingomyelin $[79,230]$. Because cholesterol is the dominant form of stored lipid, these disorders are also termed "cholesterol storage diseases" [230]. Importantly, both NPC and MLIV are associated with impaired lysosomal $\mathrm{Ca}^{2+}$ homeostasis $[228,229]$, given the decline in NAADP-mediated lysosomal $\mathrm{Ca}^{2+}$ release in NPC1 mutant human B lymphocytes and human fibroblasts [231]. Similarly, treating NPC1 mutant cells with myriocin reduces sphingosine deposition, restores lysosomal $\mathrm{Ca}^{2+}$ stores and reverses the NPC1 phenotype in WT cells [231]. Since two pore channels (TPC) have been implicated in regulating NAADP-dependent $\mathrm{Ca}^{2+}$ release [116], it is likely that sphingosine accumulation directly targets TPCs to alter lysosomal $\mathrm{Ca}^{2+}$ signal in NPC1 mutant cells. Defective $\mathrm{Ca}^{2+}$ homeostasis is also observed in Gaucher disease [232]. Microsomes isolated from the brain of a patient suffering from type II Gaucher disease exhibit 10 times higher amounts of glucosylceramide relative to control [233]. Ryanodine receptor activation increases $\mathrm{Ca}^{2+}$ release from the ER of neurons with stored glucosylceramide [234]. Similarly, GM2 accumulation in Sandhoff disease decreases the Vmax of sarco/endoplasmic reticulum $\mathrm{Ca}^{2+}$-ATPase pump (SERCA), altering the $\mathrm{Ca}^{2+}$ reuptake rate into the ER [235]. However, an outstanding question in the field is how intralysosomal lipid accumulation causes defects in ER morphology and $\mathrm{Ca}^{2+}$ homeostasis. It is possible that the lipid accumulation in the lysosome disrupts $\mathrm{Ca}^{2+}$ flux between the lysosome and ER, which likely trigger impairment in $\mathrm{Ca}^{2+}$ homeostasis. 


\subsection{Neurodegenerative Diseases}

Defective lysosomal function is also observed in neurodegenerative disorders such as Parkinson's disease (PD), Alzheimer's disease (AD), Huntington disease (HD), dementia with Lewy bodies, amyotrophic lateral sclerosis and Charcot-Marie-Tooth (CMT) disease. Lysosomes in neurodegenerative disorders exhibit disrupted and insufficient proteolysis [236], defective autophagosome-lysosome fusion [236], perturbed lysosome positioning [168] and altered lipid composition of the lysosomal membrane [237]. Failure in autophagosome clearance due to the defective lysosomal proteolytic activity and acidification is observed in AD with mutation in presenilin-1 (PS-1) [238]. Given that PS-1 is involved in the maturation of vATPase via its binding to V0a subunit, mutation in PS-1 impairs lysosomal autophagy and contributes to the pathogenesis of AD [238]. Deposition and aggregation of $\alpha$-synuclein within Lewy bodies in PD and dementia is a result of dysfunctional lysosomal autophagy [236,239]. The conditional deletion of Atg7 in dopaminergic neurons induces accumulation of low-molecular-weight- $\alpha$-synuclein and LRRK2 (leucine-rich repeat kinase 2 ), two proteins involved in the pathogenesis of idiopathic PD [240,241]. Conversely, activation of the lysosome-autophagy pathway by overexpression of TFEB or Beclin-1, or by pharmacological autophagy activator rapalog, attenuates neuronal deposition of $\alpha$-synuclein-mediated toxicity [242]. In addition to macroautophagy, wild type $\alpha$-synuclein is selectively targeted and translocated to the lysosomal lumen for degradation via CMA [243-245]. However, neuronal cells with mutations in $\alpha$-synuclein, such as A53T and A30P, binds to CMA receptor LAMP-2A, preventing their own degradation as well preventing breakdown of other CMA substrates [243,244]. Overexpression of LAMP2A upregulates CMA and increases degradation of $\alpha$-synuclein protein attenuating neurotoxicity [245].

Huntington disease (HD) is a genetic neurodegenerative disease caused by a mutation in Huntingtin (Htt) protein and displays characteristic defects in the lysosomal-autophagy pathway [246-248]. The polyglutamine-expanded huntingtin (polyQ-htt) protein is primarily degraded via lysosome-autophagy pathway [246]. Htt protein functions as a scaffold protein for selective macroautophagy. Htt interacts with cargo receptor p62, allowing it to bind to LC3 on autophagosomes [248]. Furthermore, both Htt and huntingtin-associated protein-1 (HAP1) colocalizes with autophagosomes and participates in maintaining autophagosome and lysosome dynamics in neurons [249]. By contrast, mutations in Htt compromise the ability of autophagic vacuoles to sequester cytosolic components, inducing cytotoxicity in HD [247,250]. Accumulation of lipid droplets and depolarized mitochondria in the cytosol is typically observed in neuronal and non-neuronal (MEFs) cells from HD subjects, highlighting the inability of lysosomal autophagy to recognize and degrade cytosolic content [250]. Defective lysosomal dynamics is also observed in Charcot-Marie-Tooth (CMT) disease, a genetically heterogeneous neurodegenerative disease caused by a mutation in FIG4 gene encoding $\mathrm{PI}(3,5) \mathrm{P}_{2}$ 5-phosphatase, recognized as CMT-type 4J (CMT4J) [251]. CMT4J mouse models exhibit pale tremor (plt) phenotype and suffer from multi-organ disorder with peripheral neuronopathy, central nervous system degeneration and diluted pigmentation [251-253]. Importantly, fibroblasts, isolated from skin biopsies of CMT4J patients and CMT4J mice, display enlarged vacuoles that stain positive for LAMP-2 with concomitant impairments in the late endosome-lysosome pathway [251,252]. Furthermore, these enlarged vacuoles interfere with intracellular organelle trafficking and fail to properly incorporate cargo for processing within the late endosome-lysosome compartments [251].

\subsection{Cardiovascular Diseases}

Defective lysosomal functioning is observed in cardiovascular diseases [254] and in multiple cells types given the hetero-cellularity of the heart. For e.g., the autophagy-lysosome pathway within macrophages plays an important role during atherosclerosis [254]. Macrophage-specific autophagy is important for lipid clearance [254], whereas autophagy-deficient macrophages remodel to be atherogenic in murine and human atherosclerotic lesions [254,255]. Upregulating the lysosome-autophagy pathway in macrophages either by overexpressing TFEB or treatment with the natural sugar trehalose, reverses autophagic dysfunction and attenuates macrophage apoptosis and 
pro-inflammatory IL-1 $\beta$ levels [254,255]. Moreover, macrophage-specific ATG5-null mice exhibit high atherosclerotic plaque formation and activation in a proatherogenic inflammasome [256]. In contrast, haploinsufficient Beclin-1 heterozygous-null mice do not display atherosclerotic phenotype, suggesting that the basal level of autophagy is crucial for atheroprotection [256]. Using a cell culture model of atherosclerosis, macrophages with high levels of oxidized-LDL and cholesterol crystals display an increase in lysosome $\mathrm{pH}$, suppression of lysosomal proteolytic capacity and lysosomal dysfunction [257]. Macrophage-specific TFEB-overexpressing transgenic mice exhibit increased lysosome biogenesis and proteolytic capacity in macrophages with atherogenic lipids [257]. Furthermore, the lysosome-autophagy pathway is dysfunctional in mice with ischemia/reperfusion (IR) injury and in cardiac macrophages of humans with ischemic cardiomyopathy [258]. Transgenic mice with macrophage-specific TFEB overexpression demonstrate attenuated ventricular dysfunction and IL-1 $\beta$ secretion post IR injury, likely due to upregulation of lysosomal acid lipase [258].

Moreover, our laboratory also examined the importance of the lysosome-autophagy pathway in cardiomyocytes, specifically in a model of doxorubicin (DOX)-induced cardiotoxicity [259]. Indeed, we demonstrated that DOX negatively targets TFEB to suppress lysosome abundance and proteolytic functioning in cardiomyocytes, rendering cardiomyocytes susceptible to cell death [259]. Importantly, restoration of TFEB content using adenoviruses attenuated DOX-induced suppression in lysosome number, cathepsin activity and autophagy, and TFEB restoration also reduced DOX-induced increases in reactive oxygen species and cardiomyocyte injury [259]. Similarly, impairment in the lysosome-autophagy athway and decreases in lysosomal proteolytic activity is observed in the heart of type-1 diabetic Akita mice and mice fed high-fat high-sucrose diet for 16 weeks [260]. Notably, using an ex-vivo model of nutrient overload, we demonstrated that the saturated fatty acid palmitate decreases cellular TFEB levels resulting in decreased lysosomal content, suppressed lysosomal proteolytic capacity, impaired lysosome-autophagy function, and augmented cardiomyocyte injury [260]. These findings suggest that lysosome function is crucial for maintaining cardiomyocyte homeostasis and cardiomyocyte function.

Prior studies in humans have also highlighted the link between cardiac function and lysosome function in patients with Danon's disease, which is characterized by an accumulation of intracytoplasmic vacuoles containing autophagic cargoes and glycogen in skeletal and cardiac muscle cells, resulting in X-linked vacuolar cardiomyopathy and myopathy [261-263]. LAMP2-deficient mice also displayed an accumulation of autophagic vacuoles in cardiomyocytes, along with reduced ejection fraction and reduced cardiac output compared to wild type mice $[261,263]$. These findings suggest that non-degraded autophagic vacuoles, due to deficiency of the lysosomal membrane protein LAMP2A, is causal for depressed cardiac function in patients with Danon's disease [261]. The majority of previous research on lysosomal function, signaling and metabolism have been performed in non-cardiomyocytes, requiring a thorough investigation as to how intricacies of lysosomal signaling, transport, exocytosis and biogenesis pathways are involved in cardiac health and disease.

\section{Conclusion and Perspective}

Classically, the lysosome is regarded as an organelle with distinct sorting, secretory and proteolytic function; however, newer data suggest that the lysosome is a metabolically active organelle dictating cellular homeostasis. In this review, we describe mechanisms of lysosomal sorting, biogenesis, functioning, positioning, and contact site formation. We also discuss how lysosome signaling events integrate with cellular metabolism specifically (1) discussing a modern view of lysosome sorting and positioning; (2) describing newer findings in processes targeting lysosomal size, positioning, contact site formation and biogenesis and how they are perturbed by metabolic changes; (3) providing an overview on lysosome ion mobilization and transport and its intricacies in relation to metabolic pathways and finally; (4) listing the challenges in translating these findings to treat diseases arising from aberrant lysosomal signaling, metabolism and function. Disruption or interference in lysosomal function, either by genetic mutations or loss of lysosomal protein function, is causative for lysosomal 
storage diseases, neurodegenerative diseases, cancer, cardiovascular diseases and metabolic disorders. Systemic approaches such as transcriptomics, metabolomics and proteomics and also imaging in diverse cells and organisms has added clarity to uncovering processes involved in maintaining lysosome function. However, we acknowledge that we have not discussed how hormones, vasculature, and neural inputs regulate lysosomal function. Furthermore, tissue specific transcriptional effectors of lysosome signaling are largely understudied. Despite the existing knowledge in understanding the multifaceted and heterogeneous role of the lysosome in regulating cellular homeostasis, there are numerous outstanding questions that still merit investigation.

Author Contributions: P.C.T., J.J.B. and T.P. wrote and edited the manuscript. All authors have read and agreed with the final version of this manuscript.

Funding: This work was supported by Natural Sciences and Engineering Research Council of Canada (RGPIN-2014-03687), and Diabetes Canada (NOD_OG-3-15-5037-TP \& NOD_SC-5-16-5054-TP) grants to T.P.; a Scotia Award Foundation doctoral fellowship to P.T.

Conflicts of Interest: The authors declare no potential conflicts of interest.

\section{References}

1. De Duve, C. The lysosome turns fifty. Nat. Cell Biol. 2005, 7, 847-849. [CrossRef] [PubMed]

2. Bainton, D.F. The discovery of lysosomes. J. Cell Biol. 1981, 91, 66s-76s. [CrossRef] [PubMed]

3. Pryor, P.R.; Luzio, J.P. Delivery of endocytosed membrane proteins to the lysosome. Biochim. Biophys. Acta 2009, 1793, 615-624. [CrossRef] [PubMed]

4. Hu, Y.B.; Dammer, E.B.; Ren, R.J.; Wang, G. The endosomal-lysosomal system: from acidification and cargo sorting to neurodegeneration. Transl. Neurodegener. 2015, 4, 18. [CrossRef]

5. Jegga, A.G.; Schneider, L.; Ouyang, X.; Zhang, J. Systems biology of the autophagy-lysosomal pathway. Autophagy 2011, 7, 477-489. [CrossRef]

6. Eskelinen, E.L.; Saftig, P. Autophagy: A lysosomal degradation pathway with a central role in health and disease. Biochim. Biophys. Acta 2009, 1793, 664-673. [CrossRef]

7. Herb, M.; Gluschko, A.; Schramm, M. LC3-associated phagocytosis - The highway to hell for phagocytosed microbes. Semin. Cell Dev. Biol. 2019. [CrossRef]

8. Gray, M.A.; Choy, C.H.; Dayam, R.M.; Ospina-Escobar, E.; Somerville, A.; Xiao, X.; Ferguson, S.M.; Botelho, R.J. Phagocytosis Enhances Lysosomal and Bactericidal Properties by Activating the Transcription Factor TFEB. Curr. Biol. CB 2016, 26, 1955-1964. [CrossRef]

9. Schwake, M.; Schroder, B.; Saftig, P. Lysosomal membrane proteins and their central role in physiology. Traffic 2013, 14, 739-748. [CrossRef]

10. Saftig, P.; Klumperman, J. Lysosome biogenesis and lysosomal membrane proteins: trafficking meets function. Nat. Rev. Mol. Cell Biol. 2009, 10, 623-635. [CrossRef]

11. Xiong, J.; Zhu, M.X. Regulation of lysosomal ion homeostasis by channels and transporters. Sci. China Life Sci. 2016, 59, 777-791. [CrossRef] [PubMed]

12. Perera, R.M.; Zoncu, R. The Lysosome as a Regulatory Hub. Annu. Rev. Cell Dev. Biol. 2016, 32, $223-253$. [CrossRef] [PubMed]

13. Saffi, G.T.; Botelho, R.J. Lysosome Fission: Planning for an Exit. Trends Cell Biol. 2019, 29, 635-646. [CrossRef] [PubMed]

14. Corrotte, M.; Castro-Gomes, T. Lysosomes and plasma membrane repair. Curr. Top. Membr. 2019, 84, 1-16. [CrossRef] [PubMed]

15. De Araujo, M.E.G.; Liebscher, G.; Hess, M.W.; Huber, L.A. Lysosomal size matters. Traffic 2020, 21, 60-75. [CrossRef] [PubMed]

16. Wong, Y.C.; Kim, S.; Peng, W.; Krainc, D. Regulation and Function of Mitochondria-Lysosome Membrane Contact Sites in Cellular Homeostasis. Trends Cell Biol. 2019, 29, 500-513. [CrossRef]

17. Atakpa, P.; Thillaiappan, N.B.; Mataragka, S.; Prole, D.L.; Taylor, C.W. IP3 Receptors Preferentially Associate with ER-Lysosome Contact Sites and Selectively Deliver Ca ${ }^{2+}$ to Lysosomes. Cell Rep. 2018, 25, 3180-3193. [CrossRef] 
18. Luzio, J.P.; Pryor, P.R.; Bright, N.A. Lysosomes: Fusion and function. Nat. Rev. Mol. Cell Biol. 2007, 8, 622-632. [CrossRef]

19. Luzio, J.P.; Pryor, P.R.; Gray, S.R.; Gratian, M.J.; Piper, R.C.; Bright, N.A. Membrane traffic to and from lysosomes. Biochem. Soc. Symp. 2005, 77-86. [CrossRef]

20. Woychik, N.A.; Cardelli, J.A.; Dimond, R.L. A conformationally altered precursor to the lysosomal enzyme alpha-mannosidase accumulates in the endoplasmic reticulum in a mutant strain of Dictyostelium discoideum. J. Biol. Chem. 1986, 261, 9595-9602.

21. Doray, B.; Ghosh, P.; Griffith, J.; Geuze, H.J.; Kornfeld, S. Cooperation of GGAs and AP-1 in packaging MPRs at the trans-Golgi network. Science 2002, 297, 1700-1703. [CrossRef] [PubMed]

22. Seaman, M.N. Cargo-selective endosomal sorting for retrieval to the Golgi requires retromer. J. Cell Biol. 2004, 165, 111-122. [CrossRef] [PubMed]

23. Sachse, M.; Urbe, S.; Oorschot, V.; Strous, G.J.; Klumperman, J. Bilayered clathrin coats on endosomal vacuoles are involved in protein sorting toward lysosomes. Mol. Biol. Cell 2002, 13, 1313-1328. [CrossRef] [PubMed]

24. Abubakar, Y.S.; Zheng, W.; Olsson, S.; Zhou, J. Updated Insight into the Physiological and Pathological Roles of the Retromer Complex. Int. J. Mol. Sci. 2017, 18, 1601. [CrossRef]

25. Wandinger-Ness, A.; Zerial, M. Rab proteins and the compartmentalization of the endosomal system. Cold Spring Harb. Perspect. Biol. 2014, 6, a022616. [CrossRef]

26. Rink, J.; Ghigo, E.; Kalaidzidis, Y.; Zerial, M. Rab conversion as a mechanism of progression from early to late endosomes. Cell 2005, 122, 735-749. [CrossRef]

27. Braulke, T.; Bonifacino, J.S. Sorting of lysosomal proteins. Biochim. Biophys. Acta 2009, 1793, 605-614. [CrossRef]

28. Bowman, S.L.; Bi-Karchin, J.; Le, L.; Marks, M.S. The road to lysosome-related organelles: Insights from Hermansky-Pudlak syndrome and other rare diseases. Traffic 2019, 20, 404-435. [CrossRef]

29. Ivan, V.; Martinez-Sanchez, E.; Sima, L.E.; Oorschot, V.; Klumperman, J.; Petrescu, S.M.; van der Sluijs, P. AP-3 and Rabip4' coordinately regulate spatial distribution of lysosomes. PLoS ONE 2012, 7, e48142. [CrossRef]

30. Rawlings, N.D.; Barrett, A.J.; Bateman, A. MEROPS: the peptidase database. Nucleic Acids Res. 2010, 38, D227-D233. [CrossRef]

31. Turk, V.; Stoka, V.; Vasiljeva, O.; Renko, M.; Sun, T.; Turk, B.; Turk, D. Cysteine cathepsins: from structure, function and regulation to new frontiers. Biochim. Biophys. Acta 2012, 1824, 68-88. [CrossRef] [PubMed]

32. Yogalingam, G.; Pendergast, A.M. Abl kinases regulate autophagy by promoting the trafficking and function of lysosomal components. J. Biol. Chem. 2008, 283, 35941-35953. [CrossRef] [PubMed]

33. Lutgens, E.; Lutgens, S.P.; Faber, B.C.; Heeneman, S.; Gijbels, M.M.; de Winther, M.P.; Frederik, P.; van der Made, I.; Daugherty, A.; Sijbers, A.M.; et al. Disruption of the cathepsin K gene reduces atherosclerosis progression and induces plaque fibrosis but accelerates macrophage foam cell formation. Circulation 2006, 113, 98-107. [CrossRef] [PubMed]

34. Kitamoto, S.; Sukhova, G.K.; Sun, J.; Yang, M.; Libby, P.; Love, V.; Duramad, P.; Sun, C.; Zhang, Y.; Yang, X.; et al. Cathepsin L deficiency reduces diet-induced atherosclerosis in low-density lipoprotein receptor-knockout mice. Circulation 2007, 115, 2065-2075. [CrossRef]

35. Lutgens, S.P.; Cleutjens, K.B.; Daemen, M.J.; Heeneman, S. Cathepsin cysteine proteases in cardiovascular disease. Faseb J. Off. Publ. Fed. Am. Soc. Exp. Biol. 2007, 21, 3029-3041. [CrossRef]

36. Hakala, J.K.; Oksjoki, R.; Laine, P.; Du, H.; Grabowski, G.A.; Kovanen, P.T.; Pentikainen, M.O. Lysosomal enzymes are released from cultured human macrophages, hydrolyze LDL in vitro, and are present extracellularly in human atherosclerotic lesions. Arterioscler. Thromb. Vasc. Biol. 2003, 23, 1430-1436. [CrossRef]

37. Cheng, X.W.; Shi, G.P.; Kuzuya, M.; Sasaki, T.; Okumura, K.; Murohara, T. Role for cysteine protease cathepsins in heart disease: focus on biology and mechanisms with clinical implication. Circulation 2012, 125, 1551-1562. [CrossRef]

38. Zhao, C.F.; Herrington, D.M. The function of cathepsins B, D, and X in atherosclerosis. Am. J. Cardiovasc. Dis. 2016, 6, 163-170.

39. Helske, S.; Syvaranta, S.; Kupari, M.; Lappalainen, J.; Laine, M.; Lommi, J.; Turto, H.; Mayranpaa, M.; Werkkala, K.; Kovanen, P.T.; et al. Possible role for mast cell-derived cathepsin G in the adverse remodelling of stenotic aortic valves. Eur. Heart J. 2006, 27, 1495-1504. [CrossRef] 
40. Lindstedt, K.A.; Mayranpaa, M.I.; Kovanen, P.T. Mast cells in vulnerable atherosclerotic plaques-a view to a kill. J. Cell. Mol. Med. 2007, 11, 739-758. [CrossRef]

41. Felbor, U.; Kessler, B.; Mothes, W.; Goebel, H.H.; Ploegh, H.L.; Bronson, R.T.; Olsen, B.R. Neuronal loss and brain atrophy in mice lacking cathepsins B and L. Proc. Natl. Acad. Sci. USA 2002, 99, 7883-7888. [CrossRef] [PubMed]

42. Authier, F.; Metioui, M.; Fabrega, S.; Kouach, M.; Briand, G. Endosomal proteolysis of internalized insulin at the C-terminal region of the B chain by cathepsin D. J. Biol. Chem. 2002, 277, 9437-9446. [CrossRef] [PubMed]

43. Furlanetto, R.W. Receptor-mediated endocytosis and lysosomal processing of insulin-like growth factor I by mitogenically responsive cells. Endocrinology 1988, 122, 2044-2053. [CrossRef] [PubMed]

44. Authier, F.; Kouach, M.; Briand, G. Endosomal proteolysis of insulin-like growth factor-I at its C-terminal D-domain by cathepsin B. FEBS Lett. 2005, 579, 4309-4316. [CrossRef] [PubMed]

45. Zwad, O.; Kubler, B.; Roth, W.; Scharf, J.G.; Saftig, P.; Peters, C.; Braulke, T. Decreased intracellular degradation of insulin-like growth factor binding protein-3 in cathepsin L-deficient fibroblasts. FEBS Lett. 2002, 510, 211-215. [CrossRef]

46. Hirata, E.; Ohya, Y.; Suzuki, K. Atg4 plays an important role in efficient expansion of autophagic isolation membranes by cleaving lipidated Atg8 in Saccharomyces cerevisiae. PLoS ONE 2017, 12, e0181047. [CrossRef]

47. Kaminskyy, V.; Zhivotovsky, B. Proteases in autophagy. Biochim. Biophys. Acta 2012, 1824, 44-50. [CrossRef]

48. Maruyama, T.; Noda, N.N. Autophagy-regulating protease Atg4: structure, function, regulation and inhibition. J. Antibiot. 2017. [CrossRef]

49. Yanagawa, M.; Tsukuba, T.; Nishioku, T.; Okamoto, Y.; Okamoto, K.; Takii, R.; Terada, Y.; Nakayama, K.I.; Kadowaki, T.; Yamamoto, K. Cathepsin E deficiency induces a novel form of lysosomal storage disorder showing the accumulation of lysosomal membrane sialoglycoproteins and the elevation of lysosomal $\mathrm{pH}$ in macrophages. J. Biol. Chem. 2007, 282, 1851-1862. [CrossRef]

50. Dubland, J.A.; Francis, G.A. Lysosomal acid lipase: at the crossroads of normal and atherogenic cholesterol metabolism. Front. Cell Dev. Biol. 2015, 3, 3. [CrossRef]

51. Ouimet, M.; Franklin, V.; Mak, E.; Liao, X.; Tabas, I.; Marcel, Y.L. Autophagy regulates cholesterol efflux from macrophage foam cells via lysosomal acid lipase. Cell Metab. 2011, 13, 655-667. [CrossRef] [PubMed]

52. Huang, S.C.; Everts, B.; Ivanova, Y.; O'Sullivan, D.; Nascimento, M.; Smith, A.M.; Beatty, W.; Love-Gregory, L.; Lam, W.Y.; O'Neill, C.M.; et al. Cell-intrinsic lysosomal lipolysis is essential for alternative activation of macrophages. Nat. Immunol. 2014, 15, 846-855. [CrossRef] [PubMed]

53. Xu, X.; Yuan, X.; Li, N.; Dewey, W.L.; Li, P.L.; Zhang, F. Lysosomal cholesterol accumulation in macrophages leading to coronary atherosclerosis in CD38(-/-) mice. J. Cell. Mol. Med. 2016, 20, 1001-1013. [CrossRef]

54. Jerome, W.G. Lysosomes, cholesterol and atherosclerosis. Clin. Lipidol. 2010, 5, 853-865. [CrossRef] [PubMed]

55. Coltoff-Schiller, B.; Goldfischer, S.; Wolinsky, H.; Factor, S.M. Lipid accumulation in human aortic smooth muscle cell lysosomes. Am. J. Pathol. 1976, 83, 39-44. [PubMed]

56. Jerome, W.G.; Yancey, P.G. The role of microscopy in understanding atherosclerotic lysosomal lipid metabolism. Microsc. Microanal. 2003, 9, 54-67. [CrossRef]

57. Goldfischer, S.; Schiller, B.; Wolinsky, H. Lipid accumulation in smooth muscle cell lysosomes im primate atherosclerosis. Am. J. Pathol. 1975, 78, 497-504.

58. Shio, H.; Farquhar, M.G.; de Duve, C. Lysosomes of the arterial wall. IV. Cytochemical localization of acid phosphatase and catalase in smooth muscle cells and foam cells from rabbit atheromatous aorta. Am. J. Pathol. 1974, 76, 1-16.

59. Peters, T.J.; Muller, M.; De Duve, C. Lysosomes of the arterial wall. I. Isolation and subcellular fractionation of cells from normal rabbit aorta. J. Exp. Med. 1972, 136, 1117-1139. [CrossRef]

60. Scott, S.A.; Liu, B.; Nazarenko, I.; Martis, S.; Kozlitina, J.; Yang, Y.; Ramirez, C.; Kasai, Y.; Hyatt, T.; Peter, I.; et al. Frequency of the cholesteryl ester storage disease common LIPA E8SJM mutation (c.894G $>$ A) in various racial and ethnic groups. Hepatology 2013, 58, 958-965. [CrossRef]

61. Stitziel, N.O.; Fouchier, S.W.; Sjouke, B.; Peloso, G.M.; Moscoso, A.M.; Auer, P.L.; Goel, A.; Gigante, B.; Barnes, T.A.; Melander, O.; et al. Exome sequencing and directed clinical phenotyping diagnose cholesterol ester storage disease presenting as autosomal recessive hypercholesterolemia. Arterioscler. Thromb. Vasc. Biol. 2013, 33, 2909-2914. [CrossRef] [PubMed] 
62. Du, H.; Schiavi, S.; Wan, N.; Levine, M.; Witte, D.P.; Grabowski, G.A. Reduction of atherosclerotic plaques by lysosomal acid lipase supplementation. Arterioscler. Thromb. Vasc. Biol. 2004, 24, 147-154. [CrossRef] [PubMed]

63. Maciejko, J.J. Managing Cardiovascular Risk in Lysosomal Acid Lipase Deficiency. Am. J. Cardiovasc. Drugs 2017, 17, 217-231. [CrossRef] [PubMed]

64. Su, K.; Donaldson, E.; Sharma, R. Novel treatment options for lysosomal acid lipase deficiency: critical appraisal of sebelipase alfa. Appl. Clin. Genet. 2016, 9, 157-167. [CrossRef] [PubMed]

65. Qu, P.; Du, H.; Wilkes, D.S.; Yan, C. Critical roles of lysosomal acid lipase in T cell development and function. Am. J. Pathol. 2009, 174, 944-956. [CrossRef] [PubMed]

66. Cummings, M.H.; Watts, G.F. Increased hepatic secretion of very-low-density lipoprotein apolipoprotein B-100 in cholesteryl ester storage disease. Clin. Chem. 1995, 41, 111-114. [CrossRef] [PubMed]

67. Du, H.; Heur, M.; Duanmu, M.; Grabowski, G.A.; Hui, D.Y.; Witte, D.P.; Mishra, J. Lysosomal acid lipase-deficient mice: depletion of white and brown fat, severe hepatosplenomegaly, and shortened life span. J. Lipid Res. 2001, 42, 489-500.

68. Hanson, S.R.; Best, M.D.; Wong, C.H. Sulfatases: structure, mechanism, biological activity, inhibition, and synthetic utility. Angew. Chem. 2004, 43, 5736-5763. [CrossRef]

69. Sardiello, M.; Annunziata, I.; Roma, G.; Ballabio, A. Sulfatases and sulfatase modifying factors: an exclusive and promiscuous relationship. Hum. Mol. Genet. 2005, 14, 3203-3217. [CrossRef]

70. Schmidt, B.; Selmer, T.; Ingendoh, A.; von Figura, K. A novel amino acid modification in sulfatases that is defective in multiple sulfatase deficiency. Cell 1995, 82, 271-278. [CrossRef]

71. Fujiwara, Y.; Wada, K.; Kabuta, T. Lysosomal degradation of intracellular nucleic acids-multiple autophagic pathways. J. Biochem. 2017, 161, 145-154. [CrossRef] [PubMed]

72. Fujiwara, Y.; Furuta, A.; Kikuchi, H.; Aizawa, S.; Hatanaka, Y.; Konya, C.; Uchida, K.; Yoshimura, A.; Tamai, Y.; Wada, K.; et al. Discovery of a novel type of autophagy targeting RNA. Autophagy 2013, 9, 403-409. [CrossRef] [PubMed]

73. Fujiwara, Y.; Kikuchi, H.; Aizawa, S.; Furuta, A.; Hatanaka, Y.; Konya, C.; Uchida, K.; Wada, K.; Kabuta, T. Direct uptake and degradation of DNA by lysosomes. Autophagy 2013, 9, 1167-1171. [CrossRef] [PubMed]

74. Campomenosi, P.; Salis, S.; Lindqvist, C.; Mariani, D.; Nordstrom, T.; Acquati, F.; Taramelli, R. Characterization of RNASET2, the first human member of the Rh/T2/S family of glycoproteins. Arch. Biochem. Biophys. 2006, 449, 17-26. [CrossRef] [PubMed]

75. Evans, C.J.; Aguilera, R.J. DNase II: genes, enzymes and function. Gene 2003, 322, 1-15. [CrossRef]

76. Luhtala, N.; Parker, R. T2 Family ribonucleases: ancient enzymes with diverse roles. Trends Biochem. Sci. 2010, 35, 253-259. [CrossRef]

77. Cunningham, K.W.; Fink, G.R. Calcineurin-dependent growth control in Saccharomyces cerevisiae mutants lacking PMC1, a homolog of plasma membrane $\mathrm{Ca}^{2+}$ ATPases. J. Cell Biol. 1994, 124, 351-363. [CrossRef]

78. Li, X.; Rydzewski, N.; Hider, A.; Zhang, X.; Yang, J.; Wang, W.; Gao, Q.; Cheng, X.; Xu, H. A molecular mechanism to regulate lysosome motility for lysosome positioning and tubulation. Nat. Cell Biol. 2016, 18, 404-417. [CrossRef]

79. Lloyd-Evans, E.; Platt, F.M. Lysosomal $\mathrm{Ca}^{2+}$ homeostasis: role in pathogenesis of lysosomal storage diseases. Cell Calcium 2011, 50, 200-205. [CrossRef]

80. Melchionda, M.; Pittman, J.K.; Mayor, R.; Patel, S. $\mathrm{Ca}^{2+} / \mathrm{H}^{+}$exchange by acidic organelles regulates cell migration in vivo. J. Cell Biol. 2016, 212, 803-813. [CrossRef]

81. Peters, C.; Mayer, A. $\mathrm{Ca}^{2+} /$ calmodulin signals the completion of docking and triggers a late step of vacuole fusion. Nature 1998, 396, 575-580. [CrossRef] [PubMed]

82. Pryor, P.R.; Mullock, B.M.; Bright, N.A.; Gray, S.R.; Luzio, J.P. The role of intraorganellar $\mathrm{Ca}^{2+}$ in late endosome-lysosome heterotypic fusion and in the reformation of lysosomes from hybrid organelles. J. Cell Biol. 2000, 149, 1053-1062. [CrossRef] [PubMed]

83. Marshansky, V.; Futai, M. The V-type $\mathrm{H}^{+}$-ATPase in vesicular trafficking: targeting, regulation and function. Curr. Opin. Cell Biol. 2008, 20, 415-426. [CrossRef] [PubMed]

84. Mindell, J.A. Lysosomal acidification mechanisms. Annu. Rev. Physiol. 2012, 74, 69-86. [CrossRef]

85. Johnson, D.E.; Ostrowski, P.; Jaumouille, V.; Grinstein, S. The position of lysosomes within the cell determines their luminal pH. J. Cell Biol. 2016, 212, 677-692. [CrossRef] [PubMed] 
86. Steinberg, B.E.; Huynh, K.K.; Brodovitch, A.; Jabs, S.; Stauber, T.; Jentsch, T.J.; Grinstein, S. A cation counterflux supports lysosomal acidification. J. Cell Biol. 2010, 189, 1171-1186. [CrossRef]

87. Wang, X.; Zhang, X.; Dong, X.P.; Samie, M.; Li, X.; Cheng, X.; Goschka, A.; Shen, D.; Zhou, Y.; Harlow, J.; et al. TPC proteins are phosphoinositide- activated sodium-selective ion channels in endosomes and lysosomes. Cell 2012, 151, 372-383. [CrossRef]

88. Orlowski, J.; Grinstein, S. Na ${ }^{+} / \mathrm{H}^{+}$exchangers of mammalian cells. J. Biol. Chem. 1997, 272, $22373-22376$. [CrossRef]

89. Stauber, T.; Jentsch, T.J. Chloride in vesicular trafficking and function. Annu. Rev. Physiol. 2013, 75, 453-477. [CrossRef]

90. Graves, A.R.; Curran, P.K.; Smith, C.L.; Mindell, J.A. The $\mathrm{Cl}^{-} / \mathrm{H}^{+}$antiporter $\mathrm{ClC}-7$ is the primary chloride permeation pathway in lysosomes. Nature 2008, 453, 788-792. [CrossRef]

91. Kasper, D.; Planells-Cases, R.; Fuhrmann, J.C.; Scheel, O.; Zeitz, O.; Ruether, K.; Schmitt, A.; Poet, M.; Steinfeld, R.; Schweizer, M.; et al. Loss of the chloride channel ClC-7 leads to lysosomal storage disease and neurodegeneration. EMBO J. 2005, 24, 1079-1091. [CrossRef] [PubMed]

92. Hentze, M.W.; Muckenthaler, M.U.; Andrews, N.C. Balancing acts: molecular control of mammalian iron metabolism. Cell 2004, 117, 285-297. [CrossRef]

93. Shi, H.; Bencze, K.Z.; Stemmler, T.L.; Philpott, C.C. A cytosolic iron chaperone that delivers iron to ferritin. Science 2008, 320, 1207-1210. [CrossRef] [PubMed]

94. Weber, R.A.; Yen, F.S.; Nicholson, S.P.V.; Alwaseem, H.; Bayraktar, E.C.; Alam, M.; Timson, R.C.; La, K.; Abu-Remaileh, M.; Molina, H.; et al. Maintaining Iron Homeostasis Is the Key Role of Lysosomal Acidity for Cell Proliferation. Mol. Cell 2020, 77, 645-655. [CrossRef]

95. Kidane, T.Z.; Sauble, E.; Linder, M.C. Release of iron from ferritin requires lysosomal activity. Am. J. Physiol Cell Physiol. 2006, 291, C445-C455. [CrossRef]

96. Mancias, J.D.; Wang, X.; Gygi, S.P.; Harper, J.W.; Kimmelman, A.C. Quantitative proteomics identifies NCOA4 as the cargo receptor mediating ferritinophagy. Nature 2014, 509, 105-109. [CrossRef]

97. Quiles Del Rey, M.; Mancias, J.D. NCOA4-Mediated Ferritinophagy: A Potential Link to Neurodegeneration. Front. Neurosci. 2019, 13, 238. [CrossRef]

98. Dong, X.P.; Cheng, X.; Mills, E.; Delling, M.; Wang, F.; Kurz, T.; Xu, H. The type IV mucolipidosis-associated protein TRPML1 is an endolysosomal iron release channel. Nature 2008, 455, 992-996. [CrossRef]

99. Huang, L.; Gitschier, J. A novel gene involved in zinc transport is deficient in the lethal milk mouse. Nat. Genet. 1997, 17, 292-297. [CrossRef]

100. McCormick, N.H.; Kelleher, S.L. ZnT4 provides zinc to zinc-dependent proteins in the trans-Golgi network critical for cell function and Zn export in mammary epithelial cells. Am. J. Physiol. Cell Physiol. 2012, 303, C291-C297. [CrossRef]

101. Eichelsdoerfer, J.L.; Evans, J.A.; Slaugenhaupt, S.A.; Cuajungco, M.P. Zinc dyshomeostasis is linked with the loss of mucolipidosis IV-associated TRPML1 ion channel. J. Biol. Chem. 2010, 285, 34304-34308. [CrossRef] [PubMed]

102. Sun, L.; Hua, Y.; Vergarajauregui, S.; Diab, H.I.; Puertollano, R. Novel Role of TRPML2 in the Regulation of the Innate Immune Response. J. Immunol. 2015, 195, 4922-4932. [CrossRef] [PubMed]

103. Venkatachalam, K.; Hofmann, T.; Montell, C. Lysosomal localization of TRPML3 depends on TRPML2 and the mucolipidosis-associated protein TRPML1. J. Biol. Chem. 2006, 281, 17517-17527. [CrossRef] [PubMed]

104. Medina, D.L.; Di Paola, S.; Peluso, I.; Armani, A.; De Stefani, D.; Venditti, R.; Montefusco, S.; Scotto-Rosato, A.; Prezioso, C.; Forrester, A.; et al. Lysosomal calcium signalling regulates autophagy through calcineurin and TFEB. Nat. Cell Biol. 2015, 17, 288-299. [CrossRef]

105. Zhang, X.; Cheng, X.; Yu, L.; Yang, J.; Calvo, R.; Patnaik, S.; Hu, X.; Gao, Q.; Yang, M.; Lawas, M.; et al. MCOLN1 is a ROS sensor in lysosomes that regulates autophagy. Nat. Commun. 2016, 7, 12109. [CrossRef]

106. Venkatachalam, K.; Long, A.A.; Elsaesser, R.; Nikolaeva, D.; Broadie, K.; Montell, C. Motor deficit in a Drosophila model of mucolipidosis type IV due to defective clearance of apoptotic cells. Cell 2008, 135, 838-851. [CrossRef]

107. Samie, M.A.; Xu, H. Lysosomal exocytosis and lipid storage disorders. J. Lipid Res. 2014, 55, 995-1009. [CrossRef] 
108. Shen, D.; Wang, X.; Li, X.; Zhang, X.; Yao, Z.; Dibble, S.; Dong, X.P.; Yu, T.; Lieberman, A.P.; Showalter, H.D.; et al. Lipid storage disorders block lysosomal trafficking by inhibiting a TRP channel and lysosomal calcium release. Nat. Commun. 2012, 3, 731. [CrossRef]

109. Karacsonyi, C.; Miguel, A.S.; Puertollano, R. Mucolipin-2 localizes to the Arf6-associated pathway and regulates recycling of GPI-APs. Traffic 2007, 8, 1404-1414. [CrossRef]

110. Cuajungco, M.P.; Silva, J.; Habibi, A.; Valadez, J.A. The mucolipin-2 (TRPML2) ion channel: a tissue-specific protein crucial to normal cell function. Pflug. Arch. Eur. J. Physiol. 2016, 468, 177-192. [CrossRef]

111. Remis, N.N.; Wiwatpanit, T.; Castiglioni, A.J.; Flores, E.N.; Cantu, J.A.; Garcia-Anoveros, J. Mucolipin co-deficiency causes accelerated endolysosomal vacuolation of enterocytes and failure-to-thrive from birth to weaning. PLoS Genet. 2014, 10, e1004833. [CrossRef] [PubMed]

112. Rahman, T.; Cai, X.; Brailoiu, G.C.; Abood, M.E.; Brailoiu, E.; Patel, S. Two-pore channels provide insight into the evolution of voltage-gated $\mathrm{Ca}^{2+}$ and $\mathrm{Na}^{+}$channels. Sci. Signal. 2014, 7, ra109. [CrossRef] [PubMed]

113. Xu, H.; Ren, D. Lysosomal physiology. Annu. Rev. Physiol. 2015, 77, 57-80. [CrossRef] [PubMed]

114. Lin, P.H.; Duann, P.; Komazaki, S.; Park, K.H.; Li, H.; Sun, M.; Sermersheim, M.; Gumpper, K.; Parrington, J.; Galione, A.; et al. Lysosomal two-pore channel subtype 2 (TPC2) regulates skeletal muscle autophagic signaling. J. Biol. Chem. 2015, 290, 3377-3389. [CrossRef]

115. Pereira, G.J.; Hirata, H.; Fimia, G.M.; do Carmo, L.G.; Bincoletto, C.; Han, S.W.; Stilhano, R.S.; Ureshino, R.P.; Bloor-Young, D.; Churchill, G.; et al. Nicotinic acid adenine dinucleotide phosphate (NAADP) regulates autophagy in cultured astrocytes. J. Biol. Chem. 2011, 286, 27875-27881. [CrossRef]

116. Calcraft, P.J.; Ruas, M.; Pan, Z.; Cheng, X.; Arredouani, A.; Hao, X.; Tang, J.; Rietdorf, K.; Teboul, L.; Chuang, K.T.; et al. NAADP mobilizes calcium from acidic organelles through two-pore channels. Nature 2009, 459, 596-600. [CrossRef]

117. Ruas, M.; Davis, L.C.; Chen, C.C.; Morgan, A.J.; Chuang, K.T.; Walseth, T.F.; Grimm, C.; Garnham, C.; Powell, T.; Platt, N.; et al. Expression of $\mathrm{Ca}^{2+}$-permeable two-pore channels rescues NAADP signalling in TPC-deficient cells. EMBO J. 2015, 34, 1743-1758. [CrossRef]

118. Capel, R.A.; Bolton, E.L.; Lin, W.K.; Aston, D.; Wang, Y.; Liu, W.; Wang, X.; Burton, R.A.; Bloor-Young, D.; Shade, K.T.; et al. Two-pore Channels (TPC2s) and Nicotinic Acid Adenine Dinucleotide Phosphate (NAADP) at Lysosomal-Sarcoplasmic Reticular Junctions Contribute to Acute and Chronic beta-Adrenoceptor Signaling in the Heart. J. Biol. Chem. 2015, 290, 30087-30098. [CrossRef]

119. Bazowska, G.; Jendryczko, A.; Dudkiewicz, J. Evaluation of amniotic fluid elastolytic activity: can it be a method of fetal lung maturity assessment? A comparison with Gluck's L/S test. Acta Genet. Med. Gemellol. (Roma) 1994, 43, 185-192. [CrossRef]

120. Qureshi, O.S.; Paramasivam, A.; Yu, J.C.; Murrell-Lagnado, R.D. Regulation of P2X4 receptors by lysosomal targeting, glycan protection and exocytosis. J. Cell Sci. 2007, 120, 3838-3849. [CrossRef]

121. Cao, Q.; Zhong, X.Z.; Zou, Y.; Murrell-Lagnado, R.; Zhu, M.X.; Dong, X.P. Calcium release through P2X4 activates calmodulin to promote endolysosomal membrane fusion. J. Cell Biol. 2015, 209, 879-894. [CrossRef] [PubMed]

122. Christensen, K.A.; Myers, J.T.; Swanson, J.A. pH-dependent regulation of lysosomal calcium in macrophages. J. Cell Sci. 2002, 115, 599-607. [PubMed]

123. Huang, P.; Zou, Y.; Zhong, X.Z.; Cao, Q.; Zhao, K.; Zhu, M.X.; Murrell-Lagnado, R.; Dong, X.P. P2X4 forms functional ATP-activated cation channels on lysosomal membranes regulated by luminal pH. J. Biol. Chem. 2014, 289, 17658-17667. [CrossRef] [PubMed]

124. Kilpatrick, B.S.; Eden, E.R.; Schapira, A.H.; Futter, C.E.; Patel, S. Direct mobilisation of lysosomal Ca ${ }^{2+}$ triggers complex $\mathrm{Ca}^{2+}$ signals. J. Cell Sci. 2013, 126, 60-66. [CrossRef]

125. Friedman, J.R.; Dibenedetto, J.R.; West, M.; Rowland, A.A.; Voeltz, G.K. Endoplasmic reticulum-endosome contact increases as endosomes traffic and mature. Mol. Biol. Cell 2013, 24, 1030-1040. [CrossRef]

126. Rocha, N.; Kuijl, C.; van der Kant, R.; Janssen, L.; Houben, D.; Janssen, H.; Zwart, W.; Neefjes, J. Cholesterol sensor ORP1L contacts the ER protein VAP to control Rab7-RILP-p150 Glued and late endosome positioning. J. Cell Biol. 2009, 185, 1209-1225. [CrossRef]

127. Du, X.; Kumar, J.; Ferguson, C.; Schulz, T.A.; Ong, Y.S.; Hong, W.; Prinz, W.A.; Parton, R.G.; Brown, A.J.; Yang, H. A role for oxysterol-binding protein-related protein 5 in endosomal cholesterol trafficking. J. Cell Biol. 2011, 192, 121-135. [CrossRef] 
128. Luo, J.; Jiang, L.; Yang, H.; Song, B.L. Routes and mechanisms of post-endosomal cholesterol trafficking: A story that never ends. Traffic 2017, 18, 209-217. [CrossRef]

129. Hong, Z.; Pedersen, N.M.; Wang, L.; Torgersen, M.L.; Stenmark, H.; Raiborg, C. PtdIns3P controls mTORC1 signaling through lysosomal positioning. J. Cell Biol. 2017, 216, 4217-4233. [CrossRef]

130. Ko, D.C.; Gordon, M.D.; Jin, J.Y.; Scott, M.P. Dynamic movements of organelles containing Niemann-Pick C1 protein: NPC1 involvement in late endocytic events. Mol. Biol. Cell 2001, 12, 601-614. [CrossRef]

131. Churchill, G.C.; Galione, A. NAADP induces $\mathrm{Ca}^{2+}$ oscillations via a two-pool mechanism by priming IP3and cADPR-sensitive $\mathrm{Ca}^{2+}$ stores. EMBO J. 2001, 20, 2666-2671. [CrossRef]

132. Kinnear, N.P.; Boittin, F.X.; Thomas, J.M.; Galione, A.; Evans, A.M. Lysosome-sarcoplasmic reticulum junctions. A trigger zone for calcium signaling by nicotinic acid adenine dinucleotide phosphate and endothelin-1. J. Biol. Chem. 2004, 279, 54319-54326. [CrossRef] [PubMed]

133. Zong, X.; Schieder, M.; Cuny, H.; Fenske, S.; Gruner, C.; Rotzer, K.; Griesbeck, O.; Harz, H.; Biel, M.; Wahl-Schott, C. The two-pore channel TPCN2 mediates NAADP-dependent $\mathrm{Ca}^{2+}$-release from lysosomal stores. Pflug. Arch. Eur. J. Physiol. 2009, 458, 891-899. [CrossRef]

134. Galione, A. A primer of NAADP-mediated $\mathrm{Ca}^{2+}$ signalling: From sea urchin eggs to mammalian cells. Cell Calcium 2015, 58, 27-47. [CrossRef] [PubMed]

135. Penny, C.J.; Kilpatrick, B.S.; Han, J.M.; Sneyd, J.; Patel, S. A computational model of lysosome-ER Ca ${ }^{2+}$ microdomains. J. Cell Sci. 2014, 127, 2934-2943. [CrossRef] [PubMed]

136. Garrity, A.G.; Wang, W.; Collier, C.M.; Levey, S.A.; Gao, Q.; Xu, H. The endoplasmic reticulum, not the pH gradient, drives calcium refilling of lysosomes. eLife 2016, 5. [CrossRef] [PubMed]

137. Morgan, A.J.; Davis, L.C.; Wagner, S.K.; Lewis, A.M.; Parrington, J.; Churchill, G.C.; Galione, A. Bidirectional $\mathrm{Ca}(2)(+)$ signaling occurs between the endoplasmic reticulum and acidic organelles. J. Cell Biol. 2013, 200, 789-805. [CrossRef]

138. Chen, Q.; Jin, C.; Shao, X.; Guan, R.; Tian, Z.; Wang, C.; Liu, F.; Ling, P.; Guan, J.L.; Ji, L.; et al. Super-Resolution Tracking of Mitochondrial Dynamics with An Iridium(III) Luminophore. Small 2018, 14, e1802166. [CrossRef]

139. Wong, Y.C.; Ysselstein, D.; Krainc, D. Mitochondria-lysosome contacts regulate mitochondrial fission via RAB7 GTP hydrolysis. Nature 2018, 554, 382-386. [CrossRef]

140. Baixauli, F.; Acin-Perez, R.; Villarroya-Beltri, C.; Mazzeo, C.; Nunez-Andrade, N.; Gabande-Rodriguez, E.; Ledesma, M.D.; Blazquez, A.; Martin, M.A.; Falcon-Perez, J.M.; et al. Mitochondrial Respiration Controls Lysosomal Function during Inflammatory T Cell Responses. Cell Metab. 2015, 22, 485-498. [CrossRef]

141. Fernandez-Mosquera, L.; Diogo, C.V.; Yambire, K.F.; Santos, G.L.; Luna Sanchez, M.; Benit, P.; Rustin, P.; Lopez, L.C.; Milosevic, I.; Raimundo, N. Acute and chronic mitochondrial respiratory chain deficiency differentially regulate lysosomal biogenesis. Sci Rep. 2017, 7, 45076. [CrossRef] [PubMed]

142. Mullock, B.M.; Branch, W.J.; van Schaik, M.; Gilbert, L.K.; Luzio, J.P. Reconstitution of an endosome-lysosome interaction in a cell-free system. J. Cell Biol. 1989, 108, 2093-2099. [CrossRef] [PubMed]

143. Jordens, I.; Fernandez-Borja, M.; Marsman, M.; Dusseljee, S.; Janssen, L.; Calafat, J.; Janssen, H.; Wubbolts, R.; Neefjes, J. The Rab7 effector protein RILP controls lysosomal transport by inducing the recruitment of dynein-dynactin motors. Curr. Biol. CB 2001, 11, 1680-1685. [CrossRef]

144. Marwaha, R.; Arya, S.B.; Jagga, D.; Kaur, H.; Tuli, A.; Sharma, M. The Rab7 effector PLEKHM1 binds Arl8b to promote cargo traffic to lysosomes. J. Cell Biol. 2017, 216, 1051-1070. [CrossRef] [PubMed]

145. Caplan, S.; Hartnell, L.M.; Aguilar, R.C.; Naslavsky, N.; Bonifacino, J.S. Human Vam6p promotes lysosome clustering and fusion in vivo. J. Cell Biol. 2001, 154, 109-122. [CrossRef]

146. Poupon, V.; Stewart, A.; Gray, S.R.; Piper, R.C.; Luzio, J.P. The role of mVps18p in clustering, fusion, and intracellular localization of late endocytic organelles. Mol. Biol. Cell 2003, 14, 4015-4027. [CrossRef]

147. Richardson, S.C.; Winistorfer, S.C.; Poupon, V.; Luzio, J.P.; Piper, R.C. Mammalian late vacuole protein sorting orthologues participate in early endosomal fusion and interact with the cytoskeleton. Mol. Biol. Cell 2004, 15, 1197-1210. [CrossRef]

148. Khatter, D.; Raina, V.B.; Dwivedi, D.; Sindhwani, A.; Bahl, S.; Sharma, M. The small GTPase Arl8b regulates assembly of the mammalian HOPS complex on lysosomes. J. Cell Sci. 2015, 128, 1746-1761. [CrossRef]

149. Garg, S.; Sharma, M.; Ung, C.; Tuli, A.; Barral, D.C.; Hava, D.L.; Veerapen, N.; Besra, G.S.; Hacohen, N.; Brenner, M.B. Lysosomal trafficking, antigen presentation, and microbial killing are controlled by the Arf-like GTPase Arl8b. Immunity 2011, 35, 182-193. [CrossRef] 
150. Beck, B.; Bredahl, B.; Ostermann, K.M. What consequences do the EEC directives have for our work environment? Sygeplejersken 1981, 81, 12-13.

151. Kuo, W.; Herrick, D.Z.; Ellena, J.F.; Cafiso, D.S. The calcium-dependent and calcium-independent membrane binding of synaptotagmin 1: Two modes of C2B binding. J. Mol. Biol. 2009, 387, 284-294. [CrossRef] [PubMed]

152. Antonin, W.; Holroyd, C.; Fasshauer, D.; Pabst, S.; Von Mollard, G.F.; Jahn, R. A SNARE complex mediating fusion of late endosomes defines conserved properties of SNARE structure and function. EMBO J. 2000, 19, 6453-6464. [CrossRef]

153. Parzych, K.R.; Klionsky, D.J. An overview of autophagy: Morphology, mechanism, and regulation. Antioxid. Redox Signal. 2014, 20, 460-473. [CrossRef]

154. Feng, D.; Zhao, W.L.; Ye, Y.Y.; Bai, X.C.; Liu, R.Q.; Chang, L.F.; Zhou, Q.; Sui, S.F. Cellular internalization of exosomes occurs through phagocytosis. Traffic 2010, 11, 675-687. [CrossRef] [PubMed]

155. Fitzner, D.; Schnaars, M.; van Rossum, D.; Krishnamoorthy, G.; Dibaj, P.; Bakhti, M.; Regen, T.; Hanisch, U.K.; Simons, M. Selective transfer of exosomes from oligodendrocytes to microglia by macropinocytosis. J. Cell Sci. 2011, 124, 447-458. [CrossRef] [PubMed]

156. Morelli, A.E.; Larregina, A.T.; Shufesky, W.J.; Sullivan, M.L.; Stolz, D.B.; Papworth, G.D.; Zahorchak, A.F.; Logar, A.J.; Wang, Z.; Watkins, S.C.; et al. Endocytosis, intracellular sorting, and processing of exosomes by dendritic cells. Blood 2004, 104, 3257-3266. [CrossRef] [PubMed]

157. Parton, R.G.; Dotti, C.G.; Bacallao, R.; Kurtz, I.; Simons, K.; Prydz, K. pH-induced microtubule-dependent redistribution of late endosomes in neuronal and epithelial cells. J. Cell Biol. 1991, 113, 261-274. [CrossRef]

158. McEwan, D.G.; Dikic, I. PLEKHM1: Adapting to life at the lysosome. Autophagy 2015, 11, 720-722. [CrossRef]

159. McEwan, D.G.; Popovic, D.; Gubas, A.; Terawaki, S.; Suzuki, H.; Stadel, D.; Coxon, F.P.; de Stegmann, D.M.; Bhogaraju, S.; Maddi, K.; et al. PLEKHM1 regulates autophagosome-lysosome fusion through HOPS complex and LC3/GABARAP proteins. Mol. Cell 2015, 57, 39-54. [CrossRef]

160. Jia, R.; Guardia, C.M.; Pu, J.; Chen, Y.; Bonifacino, J.S. BORC coordinates encounter and fusion of lysosomes with autophagosomes. Autophagy 2017, 13, 1648-1663. [CrossRef]

161. Nguyen, T.N.; Padman, B.S.; Usher, J.; Oorschot, V.; Ramm, G.; Lazarou, M. Atg8 family LC3/GABARAP proteins are crucial for autophagosome-lysosome fusion but not autophagosome formation during PINK1/Parkin mitophagy and starvation. J. Cell Biol. 2016, 215, 857-874. [CrossRef] [PubMed]

162. Andrews, N.W. Lysosomes and the plasma membrane: trypanosomes reveal a secret relationship. J. Cell Biol. 2002, 158, 389-394. [CrossRef] [PubMed]

163. Cardoso, C.M.; Groth-Pedersen, L.; Hoyer-Hansen, M.; Kirkegaard, T.; Corcelle, E.; Andersen, J.S.; Jaattela, M.; Nylandsted, J. Depletion of kinesin 5B affects lysosomal distribution and stability and induces peri-nuclear accumulation of autophagosomes in cancer cells. PLoS ONE 2009, 4, e4424. [CrossRef] [PubMed]

164. Reddy, A.; Caler, E.V.; Andrews, N.W. Plasma membrane repair is mediated by $\mathrm{Ca}^{2+}$-regulated exocytosis of lysosomes. Cell 2001, 106, 157-169. [CrossRef]

165. Chakrabarti, S.; Kobayashi, K.S.; Flavell, R.A.; Marks, C.B.; Miyake, K.; Liston, D.R.; Fowler, K.T.; Gorelick, F.S.; Andrews, N.W. Impaired membrane resealing and autoimmune myositis in synaptotagmin VII-deficient mice. J. Cell Biol. 2003, 162, 543-549. [CrossRef]

166. Tam, C.; Idone, V.; Devlin, C.; Fernandes, M.C.; Flannery, A.; He, X.; Schuchman, E.; Tabas, I.; Andrews, N.W. Exocytosis of acid sphingomyelinase by wounded cells promotes endocytosis and plasma membrane repair. J. Cell Biol. 2010, 189, 1027-1038. [CrossRef]

167. Idone, V.; Tam, C.; Goss, J.W.; Toomre, D.; Pypaert, M.; Andrews, N.W. Repair of injured plasma membrane by rapid $\mathrm{Ca}^{2+}$-dependent endocytosis. J. Cell Biol. 2008, 180, 905-914. [CrossRef]

168. LaPlante, J.M.; Sun, M.; Falardeau, J.; Dai, D.; Brown, E.M.; Slaugenhaupt, S.A.; Vassilev, P.M. Lysosomal exocytosis is impaired in mucolipidosis type IV. Mol. Genet. Metab. 2006, 89, 339-348. [CrossRef]

169. Paczkowski, J.E.; Richardson, B.C.; Fromme, J.C. Cargo adaptors: structures illuminate mechanisms regulating vesicle biogenesis. Trends Cell Biol. 2015, 25, 408-416. [CrossRef]

170. Renard, H.F.; Johannes, L.; Morsomme, P. Increasing Diversity of Biological Membrane Fission Mechanisms. Trends Cell Biol. 2018, 28, 274-286. [CrossRef]

171. Chen, Y.; Yu, L. Autophagic lysosome reformation. Exp. Cell Res. 2013, 319, 142-146. [CrossRef] [PubMed] 
172. Yu, L.; McPhee, C.K.; Zheng, L.; Mardones, G.A.; Rong, Y.; Peng, J.; Mi, N.; Zhao, Y.; Liu, Z.; Wan, F.; et al. Termination of autophagy and reformation of lysosomes regulated by mTOR. Nature 2010, 465, 942-946. [CrossRef] [PubMed]

173. Rong, Y.; Liu, M.; Ma, L.; Du, W.; Zhang, H.; Tian, Y.; Cao, Z.; Li, Y.; Ren, H.; Zhang, C.; et al. Clathrin and phosphatidylinositol-4,5-bisphosphate regulate autophagic lysosome reformation. Nat. Cell Biol. 2012, 14, 924-934. [CrossRef] [PubMed]

174. Sridhar, S.; Patel, B.; Aphkhazava, D.; Macian, F.; Santambrogio, L.; Shields, D.; Cuervo, A.M. The lipid kinase PI4KIIIbeta preserves lysosomal identity. EMBO J. 2013, 32, 324-339. [CrossRef]

175. Bright, N.A.; Gratian, M.J.; Luzio, J.P. Endocytic delivery to lysosomes mediated by concurrent fusion and kissing events in living cells. Curr. Biol. CB 2005, 15, 360-365. [CrossRef]

176. Heuser, J. Changes in lysosome shape and distribution correlated with changes in cytoplasmic pH. J. Cell Biol. 1989, 108, 855-864. [CrossRef]

177. Zaarur, N.; Meriin, A.B.; Bejarano, E.; Xu, X.; Gabai, V.L.; Cuervo, A.M.; Sherman, M.Y. Proteasome failure promotes positioning of lysosomes around the aggresome via local block of microtubule-dependent transport. Mol. Cell. Biol. 2014, 34, 1336-1348. [CrossRef]

178. Korolchuk, V.I.; Saiki, S.; Lichtenberg, M.; Siddiqi, F.H.; Roberts, E.A.; Imarisio, S.; Jahreiss, L.; Sarkar, S.; Futter, M.; Menzies, F.M.; et al. Lysosomal positioning coordinates cellular nutrient responses. Nat. Cell Biol. 2011, 13, 453-460. [CrossRef]

179. Bonifacino, J.S.; Neefjes, J. Moving and positioning the endolysosomal system. Curr. Opin. Cell Biol. 2017, 47, 1-8. [CrossRef]

180. Harada, A.; Takei, Y.; Kanai, Y.; Tanaka, Y.; Nonaka, S.; Hirokawa, N. Golgi vesiculation and lysosome dispersion in cells lacking cytoplasmic dynein. J. Cell Biol. 1998, 141, 51-59. [CrossRef]

181. Pu, J.; Guardia, C.M.; Keren-Kaplan, T.; Bonifacino, J.S. Mechanisms and functions of lysosome positioning. J. Cell Sci. 2016, 129, 4329-4339. [CrossRef] [PubMed]

182. Roberts, A.J. Emerging mechanisms of dynein transport in the cytoplasm versus the cilium. Biochem. Soc. Trans. 2018, 46, 967-982. [CrossRef] [PubMed]

183. Frasa, M.A.; Maximiano, F.C.; Smolarczyk, K.; Francis, R.E.; Betson, M.E.; Lozano, E.; Goldenring, J.; Seabra, M.C.; Rak, A.; Ahmadian, M.R.; et al. Armus is a Rac1 effector that inactivates Rab7 and regulates E-cadherin degradation. Curr. Biol. CB 2010, 20, 198-208. [CrossRef] [PubMed]

184. Rosa-Ferreira, C.; Munro, S. Arl8 and SKIP act together to link lysosomes to kinesin-1. Dev. Cell 2011, 21, 1171-1178. [CrossRef]

185. Loubery, S.; Wilhelm, C.; Hurbain, I.; Neveu, S.; Louvard, D.; Coudrier, E. Different microtubule motors move early and late endocytic compartments. Traffic 2008, 9, 492-509. [CrossRef]

186. Bentley, M.; Decker, H.; Luisi, J.; Banker, G. A novel assay reveals preferential binding between Rabs, kinesins, and specific endosomal subpopulations. J. Cell Biol. 2015, 208, 273-281. [CrossRef]

187. Pu, J.; Schindler, C.; Jia, R.; Jarnik, M.; Backlund, P.; Bonifacino, J.S. BORC, a multisubunit complex that regulates lysosome positioning. Dev. Cell 2015, 33, 176-188. [CrossRef]

188. Willett, R.; Martina, J.A.; Zewe, J.P.; Wills, R.; Hammond, G.R.V.; Puertollano, R. TFEB regulates lysosomal positioning by modulating TMEM55B expression and JIP4 recruitment to lysosomes. Nat. Commun. 2017, 8, 1580. [CrossRef]

189. Scotto Rosato, A.; Montefusco, S.; Soldati, C.; Di Paola, S.; Capuozzo, A.; Monfregola, J.; Polishchuk, E.; Amabile, A.; Grimm, C.; Lombardo, A.; et al. TRPML1 links lysosomal calcium to autophagosome biogenesis through the activation of the CaMKKbeta/VPS34 pathway. Nat. Commun. 2019, 10, 5630. [CrossRef]

190. Singh, R.; Cuervo, A.M. Autophagy in the cellular energetic balance. Cell Metab. 2011, 13, 495-504. [CrossRef]

191. Jin, S.M.; Youle, R.J. PINK1- and Parkin-mediated mitophagy at a glance. J. Cell Sci. 2012, 125, 795-799. [CrossRef] [PubMed]

192. Nakatogawa, H.; Mochida, K. Reticulophagy and nucleophagy: New findings and unsolved issues. Autophagy 2015, 11, 2377-2378. [CrossRef] [PubMed]

193. Oku, M.; Sakai, Y. Peroxisomes as dynamic organelles: autophagic degradation. FEBS J. 2010, 277, 3289-3294. [CrossRef] [PubMed]

194. Wen, X.; Klionsky, D.J. An overview of macroautophagy in yeast. J. Mol. Biol. 2016, 428, 1681-1699. [CrossRef]

195. Feng, Y.; He, D.; Yao, Z.; Klionsky, D.J. The machinery of macroautophagy. Cell Res. 2014, $24,24-41$. [CrossRef] 
196. Hurley, J.H.; Young, L.N. Mechanisms of Autophagy Initiation. Annu. Rev. Biochem. 2017, 86, $225-244$. [CrossRef]

197. Dall'Armi, C.; Devereaux, K.A.; Di Paolo, G. The role of lipids in the control of autophagy. Curr. Biol. CB 2013, 23, R33-R45. [CrossRef]

198. Lee, Y.K.; Lee, J.A. Role of the mammalian ATG8/LC3 family in autophagy: differential and compensatory roles in the spatiotemporal regulation of autophagy. BMB Rep. 2016, 49, 424-430. [CrossRef]

199. Tanida, I. Autophagosome formation and molecular mechanism of autophagy. Antioxid. Redox Signal. 2011, 14, 2201-2214. [CrossRef]

200. Schulze, R.J.; Sathyanarayan, A.; Mashek, D.G. Breaking fat: The regulation and mechanisms of lipophagy. Biochim. Biophys. Acta Mol. Cell Biol. Lipids 2017, 1862, 1178-1187. [CrossRef]

201. Zamani, M.; Taher, J.; Adeli, K. Complex role of autophagy in regulation of hepatic lipid and lipoprotein metabolism. J. Biomed. Res. 2017, 31,377-385. [CrossRef] [PubMed]

202. Schulze, R.J.; Drizyte, K.; Casey, C.A.; McNiven, M.A. Hepatic Lipophagy: New Insights into Autophagic Catabolism of Lipid Droplets in the Liver. Hepatol. Commun. 2017, 1, 359-369. [CrossRef] [PubMed]

203. Hammerling, B.C.; Gustafsson, A.B. Mitochondrial quality control in the myocardium: cooperation between protein degradation and mitophagy. J. Mol. Cell Cardiol. 2014, 75, 122-130. [CrossRef] [PubMed]

204. Khalil, B.; El Fissi, N.; Aouane, A.; Cabirol-Pol, M.J.; Rival, T.; Lievens, J.C. PINK1-induced mitophagy promotes neuroprotection in Huntington's disease. Cell Death Dis. 2015, 6, e1617. [CrossRef]

205. Shires, S.E.; Gustafsson, A.B. Mitophagy and heart failure. J. Mol. Med. Berl. 2015, 93, 253-262. [CrossRef] [PubMed]

206. Zhang, Y.; Liu, Q.; Li, Y.; Li, C.; Zhu, Y.; Xia, F.; Xu, S.; Li, W. PTEN-Induced Putative Kinase 1 (PINK1)/Parkin-Mediated Mitophagy Protects PC12 Cells Against Cisplatin-Induced Neurotoxicity. Med. Sci. Monit. 2019, 25, 8797-8806. [CrossRef]

207. Shaid, S.; Brandts, C.H.; Serve, H.; Dikic, I. Ubiquitination and selective autophagy. Cell Death Differ. 2013, 20, 21-30. [CrossRef]

208. Peng, H.; Yang, J.; Li, G.; You, Q.; Han, W.; Li, T.; Gao, D.; Xie, X.; Lee, B.H.; Du, J.; et al. Ubiquitylation of p62/sequestosome1 activates its autophagy receptor function and controls selective autophagy upon ubiquitin stress. Cell Res. 2017, 27, 657-674. [CrossRef]

209. Papadopoulos, C.; Kravic, B.; Meyer, H. Repair or Lysophagy: Dealing with Damaged Lysosomes. J. Mol. Biol. 2020, 432, 231-239. [CrossRef]

210. Radulovic, M.; Schink, K.O.; Wenzel, E.M.; Nahse, V.; Bongiovanni, A.; Lafont, F.; Stenmark, H. ESCRT-mediated lysosome repair precedes lysophagy and promotes cell survival. EMBO J. 2018, 37. [CrossRef]

211. Ward, C.; Martinez-Lopez, N.; Otten, E.G.; Carroll, B.; Maetzel, D.; Singh, R.; Sarkar, S.; Korolchuk, V.I. Autophagy, lipophagy and lysosomal lipid storage disorders. Biochim. Biophys. Acta 2016, 1861, 269-284. [CrossRef] [PubMed]

212. Papadopoulos, C.; Meyer, H. Detection and Clearance of Damaged Lysosomes by the Endo-Lysosomal Damage Response and Lysophagy. Curr. Biol. CB 2017, 27, R1330-R1341. [CrossRef] [PubMed]

213. Wang, F.; Salvati, A.; Boya, P. Lysosome-dependent cell death and deregulated autophagy induced by amine-modified polystyrene nanoparticles. Open Biol. 2018, 8. [CrossRef] [PubMed]

214. Chauhan, S.; Kumar, S.; Jain, A.; Ponpuak, M.; Mudd, M.H.; Kimura, T.; Choi, S.W.; Peters, R.; Mandell, M.; Bruun, J.A.; et al. TRIMs and Galectins Globally Cooperate and TRIM16 and Galectin-3 Co-direct Autophagy in Endomembrane Damage Homeostasis. Dev. Cell 2016, 39, 13-27. [CrossRef]

215. Arias, E.; Cuervo, A.M. Chaperone-mediated autophagy in protein quality control. Curr. Opin. Cell Biol. 2011, 23, 184-189. [CrossRef]

216. Cuervo, A.M.; Wong, E. Chaperone-mediated autophagy: roles in disease and aging. Cell Res. 2014, 24, 92-104. [CrossRef]

217. Alfaro, I.E.; Albornoz, A.; Molina, A.; Moreno, J.; Cordero, K.; Criollo, A.; Budini, M. Chaperone Mediated Autophagy in the Crosstalk of Neurodegenerative Diseases and Metabolic Disorders. Front. Endocrinol. Lausanne 2018, 9, 778. [CrossRef]

218. Patel, B.; Cuervo, A.M. Methods to study chaperone-mediated autophagy. Methods 2015, 75, $133-140$. [CrossRef] 
219. Sakai, Y.; Koller, A.; Rangell, L.K.; Keller, G.A.; Subramani, S. Peroxisome degradation by microautophagy in Pichia pastoris: identification of specific steps and morphological intermediates. J. Cell Biol. 1998, 141, 625-636. [CrossRef]

220. Lemasters, J.J. Variants of mitochondrial autophagy: Types 1 and 2 mitophagy and micromitophagy (Type 3). Redox Biol. 2014, 2, 749-754. [CrossRef]

221. Seo, A.Y.; Lau, P.W.; Feliciano, D.; Sengupta, P.; Gros, M.A.L.; Cinquin, B.; Larabell, C.A.; Lippincott-Schwartz, J. AMPK and vacuole-associated Atg14p orchestrate mu-lipophagy for energy production and long-term survival under glucose starvation. eLife 2017, 6. [CrossRef]

222. Meikle, P.J.; Hopwood, J.J.; Clague, A.E.; Carey, W.F. Prevalence of lysosomal storage disorders. JAMA 1999, 281, 249-254. [CrossRef] [PubMed]

223. Stirnemann, J.; Belmatoug, N.; Camou, F.; Serratrice, C.; Froissart, R.; Caillaud, C.; Levade, T.; Astudillo, L.; Serratrice, J.; Brassier, A.; et al. A Review of Gaucher Disease Pathophysiology, Clinical Presentation and Treatments. Int. J. Mol. Sci. 2017, 18. [CrossRef] [PubMed]

224. Dersh, D.; Iwamoto, Y.; Argon, Y. Tay-Sachs disease mutations in HEXA target the alpha chain of hexosaminidase A to endoplasmic reticulum-associated degradation. Mol. Biol. Cell 2016, 27, 3813-3827. [CrossRef]

225. Raben, N.; Plotz, P.; Byrne, B.J. Acid alpha-glucosidase deficiency (glycogenosis type II, Pompe disease). Curr. Mol. Med. 2002, 2, 145-166. [CrossRef]

226. Mellies, U.; Lofaso, F. Pompe disease: A neuromuscular disease with respiratory muscle involvement. Respir. Med. 2009, 103, 477-484. [CrossRef]

227. McCall, A.L.; Salemi, J.; Bhanap, P.; Strickland, L.M.; Elmallah, M.K. The impact of Pompe disease on smooth muscle: a review. J. Smooth Muscle Res. 2018, 54, 100-118. [CrossRef]

228. Seranova, E.; Connolly, K.J.; Zatyka, M.; Rosenstock, T.R.; Barrett, T.; Tuxworth, R.I.; Sarkar, S. Dysregulation of autophagy as a common mechanism in lysosomal storage diseases. Essays Biochem. 2017, 61, 733-749. [CrossRef]

229. Lieberman, A.P.; Puertollano, R.; Raben, N.; Slaugenhaupt, S.; Walkley, S.U.; Ballabio, A. Autophagy in lysosomal storage disorders. Autophagy 2012, 8, 719-730. [CrossRef]

230. Lloyd-Evans, E.; Platt, F.M. Lipids on trial: the search for the offending metabolite in Niemann-Pick type C disease. Traffic 2010, 11, 419-428. [CrossRef]

231. Lloyd-Evans, E.; Morgan, A.J.; He, X.; Smith, D.A.; Elliot-Smith, E.; Sillence, D.J.; Churchill, G.C.; Schuchman, E.H.; Galione, A.; Platt, F.M. Niemann-Pick disease type $\mathrm{C} 1$ is a sphingosine storage disease that causes deregulation of lysosomal calcium. Nat. Med. 2008, 14, 1247-1255. [CrossRef]

232. Gegg, M.E.; Schapira, A.H. Mitochondrial dysfunction associated with glucocerebrosidase deficiency. Neurobiol. Dis. 2016, 90, 43-50. [CrossRef] [PubMed]

233. Lloyd-Evans, E.; Pelled, D.; Riebeling, C.; Bodennec, J.; de-Morgan, A.; Waller, H.; Schiffmann, R.; Futerman, A.H. Glucosylceramide and glucosylsphingosine modulate calcium mobilization from brain microsomes via different mechanisms. J. Biol. Chem. 2003, 278, 23594-23599. [CrossRef] [PubMed]

234. Korkotian, E.; Schwarz, A.; Pelled, D.; Schwarzmann, G.; Segal, M.; Futerman, A.H. Elevation of intracellular glucosylceramide levels results in an increase in endoplasmic reticulum density and in functional calcium stores in cultured neurons. J. Biol. Chem. 1999, 274, 21673-21678. [CrossRef] [PubMed]

235. Pelled, D.; Lloyd-Evans, E.; Riebeling, C.; Jeyakumar, M.; Platt, F.M.; Futerman, A.H. Inhibition of calcium uptake via the sarco/endoplasmic reticulum $\mathrm{Ca}^{2+}$-ATPase in a mouse model of Sandhoff disease and prevention by treatment with N-butyldeoxynojirimycin. J. Biol. Chem. 2003, 278, 29496-29501. [CrossRef] [PubMed]

236. Nixon, R.A. The role of autophagy in neurodegenerative disease. Nat. Med. 2013, 19, 983-997. [CrossRef]

237. Appelqvist, H.; Sandin, L.; Bjornstrom, K.; Saftig, P.; Garner, B.; Ollinger, K.; Kagedal, K. Sensitivity to lysosome-dependent cell death is directly regulated by lysosomal cholesterol content. PLoS ONE 2012, 7, e50262. [CrossRef]

238. Lee, J.H.; Yu, W.H.; Kumar, A.; Lee, S.; Mohan, P.S.; Peterhoff, C.M.; Wolfe, D.M.; Martinez-Vicente, M.; Massey, A.C.; Sovak, G.; et al. Lysosomal proteolysis and autophagy require presenilin 1 and are disrupted by Alzheimer-related PS1 mutations. Cell 2010, 141, 1146-1158. [CrossRef]

239. Lee, H.J.; Khoshaghideh, F.; Patel, S.; Lee, S.J. Clearance of alpha-synuclein oligomeric intermediates via the lysosomal degradation pathway. J. Neurosci. Off. J. Soc. Neurosci. 2004, 24, 1888-1896. [CrossRef] 
240. Ahmed, I.; Liang, Y.; Schools, S.; Dawson, V.L.; Dawson, T.M.; Savitt, J.M. Development and characterization of a new Parkinson's disease model resulting from impaired autophagy. J. Neurosci. Off. J. Soc. Neurosci. 2012, 32, 16503-16509. [CrossRef]

241. Friedman, L.G.; Lachenmayer, M.L.; Wang, J.; He, L.; Poulose, S.M.; Komatsu, M.; Holstein, G.R.; Yue, Z. Disrupted autophagy leads to dopaminergic axon and dendrite degeneration and promotes presynaptic accumulation of alpha-synuclein and LRRK2 in the brain. J. Neurosci. Off. J. Soc. Neurosci. 2012, 32, 7585-7593. [CrossRef] [PubMed]

242. Decressac, M.; Mattsson, B.; Weikop, P.; Lundblad, M.; Jakobsson, J.; Bjorklund, A. TFEB-mediated autophagy rescues midbrain dopamine neurons from alpha-synuclein toxicity. Proc. Natl. Acad. Sci. USA 2013, 110, E1817-E1826. [CrossRef] [PubMed]

243. Cuervo, A.M.; Stefanis, L.; Fredenburg, R.; Lansbury, P.T.; Sulzer, D. Impaired degradation of mutant alpha-synuclein by chaperone-mediated autophagy. Science 2004, 305, 1292-1295. [CrossRef] [PubMed]

244. Vogiatzi, T.; Xilouri, M.; Vekrellis, K.; Stefanis, L. Wild type alpha-synuclein is degraded by chaperonemediated autophagy and macroautophagy in neuronal cells. J. Biol. Chem. 2008, 283, 23542-23556. [CrossRef] [PubMed]

245. Xilouri, M.; Brekk, O.R.; Landeck, N.; Pitychoutis, P.M.; Papasilekas, T.; Papadopoulou-Daifoti, Z.; Kirik, D.; Stefanis, L. Boosting chaperone-mediated autophagy in vivo mitigates alpha-synuclein-induced neurodegeneration. Brain J. Neurol. 2013, 136, 2130-2146. [CrossRef]

246. Cortes, C.J.; La Spada, A.R. The many faces of autophagy dysfunction in Huntington's disease: from mechanism to therapy. Drug Discov. Today 2014, 19, 963-971. [CrossRef]

247. Harding, R.J.; Tong, Y.F. Proteostasis in Huntington's disease: disease mechanisms and therapeutic opportunities. Acta Pharmacol. Sin. 2018, 39, 754-769. [CrossRef]

248. Rui, Y.N.; Xu, Z.; Patel, B.; Chen, Z.; Chen, D.; Tito, A.; David, G.; Sun, Y.; Stimming, E.F.; Bellen, H.J.; et al. Huntingtin functions as a scaffold for selective macroautophagy. Nat. Cell Biol. 2015, 17, 262-275. [CrossRef]

249. Wong, Y.C.; Holzbaur, E.L. The regulation of autophagosome dynamics by huntingtin and HAP1 is disrupted by expression of mutant huntingtin, leading to defective cargo degradation. J. Neurosci. Off. J. Soc. Neurosci. 2014, 34, 1293-1305. [CrossRef]

250. Martinez-Vicente, M.; Talloczy, Z.; Wong, E.; Tang, G.; Koga, H.; Kaushik, S.; de Vries, R.; Arias, E.; Harris, S.; Sulzer, D.; et al. Cargo recognition failure is responsible for inefficient autophagy in Huntington's disease. Nat. Neurosci. 2010, 13, 567-576. [CrossRef]

251. Zhang, X.; Chow, C.Y.; Sahenk, Z.; Shy, M.E.; Meisler, M.H.; Li, J. Mutation of FIG4 causes a rapidly progressive, asymmetric neuronal degeneration. Brain J. Neurol. 2008, 131, 1990-2001. [CrossRef] [PubMed]

252. Chow, C.Y.; Zhang, Y.; Dowling, J.J.; Jin, N.; Adamska, M.; Shiga, K.; Szigeti, K.; Shy, M.E.; Li, J.; Zhang, X.; et al. Mutation of FIG4 causes neurodegeneration in the pale tremor mouse and patients with CMT4J. Nature 2007, 448, 68-72. [CrossRef] [PubMed]

253. Martyn, C.; Li, J. Fig4 deficiency: A newly emerged lysosomal storage disorder? Prog. Neurobiol. 2013, 101-102, 35-45. [CrossRef] [PubMed]

254. Sergin, I.; Evans, T.D.; Razani, B. Degradation and beyond: the macrophage lysosome as a nexus for nutrient sensing and processing in atherosclerosis. Curr. Opin. Lipidol. 2015, 26, 394-404. [CrossRef] [PubMed]

255. Sergin, I.; Evans, T.D.; Zhang, X.; Bhattacharya, S.; Stokes, C.J.; Song, E.; Ali, S.; Dehestani, B.; Holloway, K.B.; Micevych, P.S.; et al. Exploiting macrophage autophagy-lysosomal biogenesis as a therapy for atherosclerosis. Nat. Commun. 2017, 8, 15750. [CrossRef] [PubMed]

256. Razani, B.; Feng, C.; Coleman, T.; Emanuel, R.; Wen, H.; Hwang, S.; Ting, J.P.; Virgin, H.W.; Kastan, M.B.; Semenkovich, C.F. Autophagy links inflammasomes to atherosclerotic progression. Cell Metab. 2012, 15, 534-544. [CrossRef] [PubMed]

257. Emanuel, R.; Sergin, I.; Bhattacharya, S.; Turner, J.; Epelman, S.; Settembre, C.; Diwan, A.; Ballabio, A.; Razani, B. Induction of lysosomal biogenesis in atherosclerotic macrophages can rescue lipid-induced lysosomal dysfunction and downstream sequelae. Arterioscler. Thromb. Vasc. Biol. 2014, 34, 1942-1952. [CrossRef]

258. Javaheri, A.; Bajpai, G.; Picataggi, A.; Mani, S.; Foroughi, L.; Evie, H.; Kovacs, A.; Weinheimer, C.J.; Hyrc, K.; Xiao, Q.; et al. TFEB activation in macrophages attenuates postmyocardial infarction ventricular dysfunction independently of ATG5-mediated autophagy. JCI Insight 2019, 4. [CrossRef] 
259. Bartlett, J.J.; Trivedi, P.C.; Yeung, P.; Kienesberger, P.C.; Pulinilkunnil, T. Doxorubicin impairs cardiomyocyte viability by suppressing transcription factor EB expression and disrupting autophagy. Biochem. J. 2016, 473, 3769-3789. [CrossRef]

260. Trivedi, P.C.; Bartlett, J.J.; Perez, L.J.; Brunt, K.R.; Legare, J.F.; Hassan, A.; Kienesberger, P.C.; Pulinilkunnil, T. Glucolipotoxicity diminishes cardiomyocyte TFEB and inhibits lysosomal autophagy during obesity and diabetes. Biochim. Biophys. Acta 2016, 1861, 1893-1910. [CrossRef]

261. Nishino, I.; Fu, J.; Tanji, K.; Yamada, T.; Shimojo, S.; Koori, T.; Mora, M.; Riggs, J.E.; Oh, S.J.; Koga, Y.; et al. Primary LAMP-2 deficiency causes X-linked vacuolar cardiomyopathy and myopathy (Danon disease). Nature 2000, 406, 906-910. [CrossRef] [PubMed]

262. Stypmann, J.; Janssen, P.M.; Prestle, J.; Engelen, M.A.; Kogler, H.; Lullmann-Rauch, R.; Eckardt, L.; von Figura, K.; Landgrebe, J.; Mleczko, A.; et al. LAMP-2 deficient mice show depressed cardiac contractile function without significant changes in calcium handling. Basic Res. Cardiol. 2006, 101, 281-291. [CrossRef] [PubMed]

263. Sugimoto, S.; Shiomi, K.; Yamamoto, A.; Nishino, I.; Nonaka, I.; Ohi, T. LAMP-2 positive vacuolar myopathy with dilated cardiomyopathy. Intern. Med. 2007, 46, 757-760. [CrossRef] [PubMed]

(C) 2020 by the authors. Licensee MDPI, Basel, Switzerland. This article is an open access article distributed under the terms and conditions of the Creative Commons Attribution (CC BY) license (http://creativecommons.org/licenses/by/4.0/). 